\title{
Malaria Transmission Blocking Vaccines
}

\author{
Lukasz Jacek Sewera \\ Loyola University Chicago
}

Follow this and additional works at: https://ecommons.luc.edu/luc_theses

Part of the Virology Commons

\section{Recommended Citation}

Sewera, Lukasz Jacek, "Malaria Transmission Blocking Vaccines" (2015). Master's Theses. 3149.

https://ecommons.luc.edu/luc_theses/3149

This Thesis is brought to you for free and open access by the Theses and Dissertations at Loyola eCommons. It has been accepted for inclusion in Master's Theses by an authorized administrator of Loyola eCommons. For more information, please contact ecommons@luc.edu. (c) (i) $(9)$

This work is licensed under a Creative Commons Attribution-Noncommercial-No Derivative Works 3.0 License. Copyright (C) 2015 Lukasz Jacek Sewera 
LOYOLA UNIVERSITY CHICAGO

MALARIA TRANSMISSION BLOCKING VACCINES

A THESIS SUBMITTED TO

THE FACULTY OF THE GRADUATE SCHOOL IN CANDIDACY FOR THE DEGREE OF

MASTER OF SCIENCE

PROGRAM IN MICROBIOLOGY AND IMMUNOLOGY

BY

LUKASZ SEWERA

CHICAGO, IL

DECEMBER 2015 
Copyright by Lukasz Sewera, 2015 All rights reserved. 


\section{ACKNOWLEDGEMENTS}

I would like to thank Dr. Chris Wiethoff for being my mentor and helping me develop the ideas in my project. Chris has always been available to discuss new ideas and fosters a collaborative environment in lab. I want to thank the other members of the lab for helping me with experiments and for always being willing to show me new techniques. All the members of our lab made my experience in graduate school much more enjoyable. I would also like to thank the members of my thesis committee for providing feedback on my project and helping me stay on track. The environment in the Department of Microbiology and Immunology has been very supportive and I want to thank everyone in the department. I want to thank my family and friends for their support throughout my education. They have always been around to provide valuable advice and support. 
TABLE OF CONTENTS

ACKNOWLEDGEMENTS

LIST OF FIGURES $\quad$ vi

ABSTRACT vii

CHAPTER ONE: REVIEW OF LITERATURE

Malaria: epidemiology 1

Malaria: lifecycle and disease $\quad 3$

Malaria: host response $\quad 6$

$\begin{array}{ll}\text { Malaria: current treatments } & 7\end{array}$

Malaria: approaches to eradication $\quad 8$

$\begin{array}{ll}\text { Malaria: vaccine development } & 10\end{array}$

Malaria: transmission blocking vaccines $\quad 13$

$\begin{array}{ll}\text { Pfs25 } & 14\end{array}$

Pfs25: structure $\quad 15$

Antibody response to vaccines 19

$\begin{array}{ll}\text { Vaccine adjuvants } & 21\end{array}$

$\begin{array}{ll}\text { Adenovirus } & 23\end{array}$

$\begin{array}{ll}\text { Adenovirus vaccine vectors } & 24\end{array}$

$\begin{array}{ll}\text { Improving Ad vectors for TBV } & 26\end{array}$

CHAPTER TWO: MATERIALS AND METHODS 27

$\begin{array}{ll}\text { Cell lines and cell culture } & 27\end{array}$

$\begin{array}{ll}\text { Recombinant virus construction } & 27\end{array}$

Virus purification and titering $\quad 28$

Reagents and antibodies $\quad 29$

ELISA $\quad 29$

Mice and immunizations $\quad 30$

Pfs25 domain synthesis and purification $\quad 31$

SDS-PAGE and Western blots 33

$\begin{array}{ll}\text { Statistics } & 34\end{array}$

CHAPTER THREE: RESULTS

EGF domain expression $\quad 35$

Refolding of domains from Pfs25 38

Pfs25 expression by cells infected with Ad5Pfs25exo 42 
Antibody response to immunization with Ad5Pfs25exo

Domain specific antibody response to immunization with Ad5Pfs25exo

Domain specific antibody response to $\mathrm{Ad}_{\mathrm{CD}}$ vectors

Transmission blocking activity of serum from mice immunized with $\mathrm{Ad}_{\mathrm{CD}}$

A new epitope from domain 3

Antibody response to $\mathrm{Ad}_{\mathrm{CD}}$ vectors with $\mathrm{FliC}$

CHAPTER FOUR: DISCUSSION

Refolding of Pfs 25 domain 3

Domain specific ELISA

Creating new $\mathrm{Ad}_{\mathrm{CD}}$ vectors

Focusing the antibody response to transmission blocking epitopes

61

Effect of capsid displayed FliC on antibody response to $\mathrm{Ad}_{\mathrm{CD}}$ vectors

62

Concluding remarks 


\section{LIST OF FIGURES}

Figure

Page

1. Global distribution of malaria

2. Plasmodium falciparum lifecycle 5

3. Pfs25 protein model 17

4. Domain 3 expression in E. coli 35

5. Purified domain 3 protein gel 38

6. $\quad$ ELISA titers to domain 3 using ID2 and 4B7 39

7. Expression of Ad5Pfs25exo by $293 \beta 5$ cells 41

8. Anti-Pfs25 ELISA titers for Ad5Pfs25exo 43

9. Domain specific ELISA titers for Ad5Pfs25exo and Ad5Pfs25 45

10. Domain specific ELISA titers for $\mathrm{Ad}_{\mathrm{CD}} \quad 47$

11. SMFA with Ad5Pfs25/Pfs25-alum and Ad5Pfs25/Ad

12. ELISA titers to new capsid displayed antigen D3C 51

13. Anti-Pfs25 ELISA titers for $\mathrm{Ad}_{\mathrm{CD}} \mathrm{PF}$

14. Anti-capsid ELISA titers for $\mathrm{Ad}_{\mathrm{CD}} \mathrm{PF}$ 


\begin{abstract}
Malaria affects 198 million people and kills 584,000 each year, predominantly in Sub-Saharan Africa (WHO). The most severe form of malaria is caused by the protozoan parasite Plasmodium falciparum. Development of a vaccine against $P$. falciparum has been hindered by its complex life cycle with multiple antigenically distinct human and mosquito stages. To effectively prevent disease and reduce the parasite burden in populations, a vaccine will need to target multiple stages, including blocking transmission at the mosquito stage.

Antibodies generated against $P$. falciparum mosquito stage antigen Pfs 25 can prevent parasite transmission from humans to mosquitoes. However, Pfs 25 is poorly immunogenic and immunization with the protein with alum as an adjuvant does not provide adequate transmission blocking activity. In this study I used adenovirus vectors (Ad) modified to express Pfs25 as a transgene or with capsid displayed Pfs25 epitopes to elicit a stronger anti-Pfs 25 antibody response specifically directed at epitopes highly associated with transmission blocking.

Although antibody titers are closely associated with transmission blocking activity, it is unlikely that all antibodies generated by immunization with whole protein are transmission blocking. Based on molecular models, EGF-like domains 2 and 3 appear to be most surface accessible on the parasite surface. However, antibodies raised against soluble Pfs 25 equally recognize all 4 EGF-like domains. Thus, a vaccine involving in situ vii
\end{abstract}


expression of membrane anchored Pfs 25 may better target antibody responses to domains 2 and 3. Additionally, using secondary immunization with capsid displayed Pfs25, I expected to further direct the antibody response to predicted B cell epitopes. Serum from mice immunized with these vectors can provide transmission blocking activity with lower antibody titers.

Innate immune responses to $\mathrm{Ad}$ are an important component of generating adaptive immunity and may provide a means to further augment antibody responses to poorly immunogenic protein antigens. Molecules such as Pseudomonas aeruginosa flagellin (FliC) potently activate the innate immune system and could be used to modify vectors to induce greater adaptive immunity. We have generated Ad vectors with FliC attached to protein IX. Using these vectors with capsid displayed Pfs25 epitopes I assessed whether capsid displayed FliC increases antibody titers to Pfs25. 


\section{CHAPTER ONE \\ REVIEW OF LITERATURE}

\section{Malaria: epidemiology}

Malaria is a mosquito borne illness caused by protozoan parasites in the genus

Plasmodium. According to the 2014 World Malaria Report, 198 million cases and 584,000 deaths as a result of malaria were recorded in 97 countries. $90 \%$ of deaths were in Africa. Worldwide, approximately 3.3 billion people are at risk of malaria and 1.2 billion are at high risk (Figure 1). However, since 2000, prevalence of malaria and deaths due to malaria have decreased despite population growth in malaria endemic areas. This decrease has been due to aggressive efforts to prevent parasite transmission and ongoing efforts are necessary to maintain this trend (WHO). 


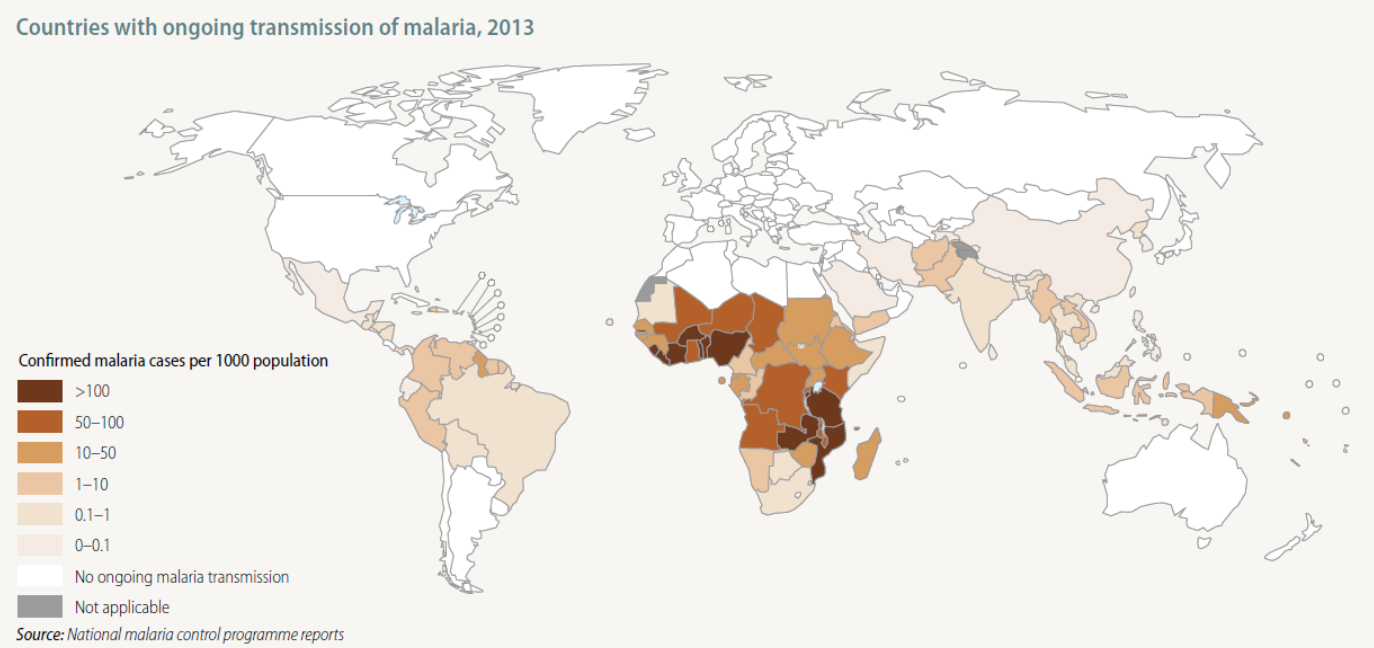

Figure 1: Global incidence of malaria in 2013. Most cases of malaria are concentrated in Sub-Saharan Africa. 


\section{Malaria: lifecycle and disease}

Malaria is caused by multiple Plasmodium spp, however, P.falciparum causes the most severe and life threatening illness and is responsible for $90 \%$ of mortality due to malaria (Snow 2015). The lifecycle of P. falciparum is complex and involves several antigenically and morphologically distinct stages. Sporozoites are the infectious stage of Plasmodium spp. and are transmitted by Anopheles spp. mosquitoes. While the mosquito feeds on its host, sporozoites in the salivary glands enter the bloodstream and travel to the liver. After invading hepatocytes, sporozoites divide many times to form schizonts. Schizonts contain thousands of merozoites, which enter the bloodstream when schizonts rupture 6 to 30 days post infection. Circulating merozoites invade red blood cells (RBC) and undergo maturation to schizonts over 48 hours. Infection of RBC causes multiple morphologic changes that lead to increased splenic clearance of RBC and anemia. Structural changes in the RBC surface can also lead to obstruction of small vessels which is especially problematic in the kidney and brain. After maturation is complete, schizonts rupture and $\mathrm{RBC}$ lyse, releasing merozoites that can then infect new cells. RBC lysis releases cell membrane remnants and hemoglobin degradation products, which are phagocytosed by macrophages and can also activate endothelial cells. This activation of immune cascades leads to release of pro-inflammatory cytokines, which suppress hematopoiesis and exacerbate anemia that results from parasite induced splenic clearance of RBC (McDevitt et al. 2004).

While the majority of merozoites undergo this asexual cycle, some differentiate into male and female gametocytes and undergo a 3-4 day maturation process after which 
they are released into the blood. Gametocytes make up only $1.8-5.7 \%$ of total parasitemia in blood (Ouedraogo et al. 2010). Mature gametocytes circulate in the bloodstream and can be ingested by a feeding mosquito. In the mosquito midgut, $\mathrm{pH}$, temperature change and xanthurenic acid cause gametocytes to differentiate into male and female gametocytes. Male and female gametocytes mate to produce zygotes which develop into ookinetes and penetrate the gut wall. Ookinetes become oocysts, which eventually release sporozoites. Sporozoites migrate to the salivary glands and can initiate a new cycle of infection when the mosquito feeds on a new host (Leroy et al. 2014).

The initial incubation stage of malaria is asymptomatic and lasts 12-14 days for P. falciparum. The incubation period can last longer due to partial immunity or ineffective prophylaxis (Schwartz et al. 2003). Symptoms occur during the erythrocytic stage and are a result of $\mathrm{RBC}$ lysis and release of pro inflammatory cytokines. Malaria begins with non-specific symptoms such as fever, malaise and fatigue. When merozoites are present in the serum, they can be visualized by microscopy of blood smears. In some cases malaria can become severe, especially with P. falciparum. Severe malaria often results from vascular occlusion by infected RBC and can include organ failure and cerebral malaria (WHO: Severe Malaria). 


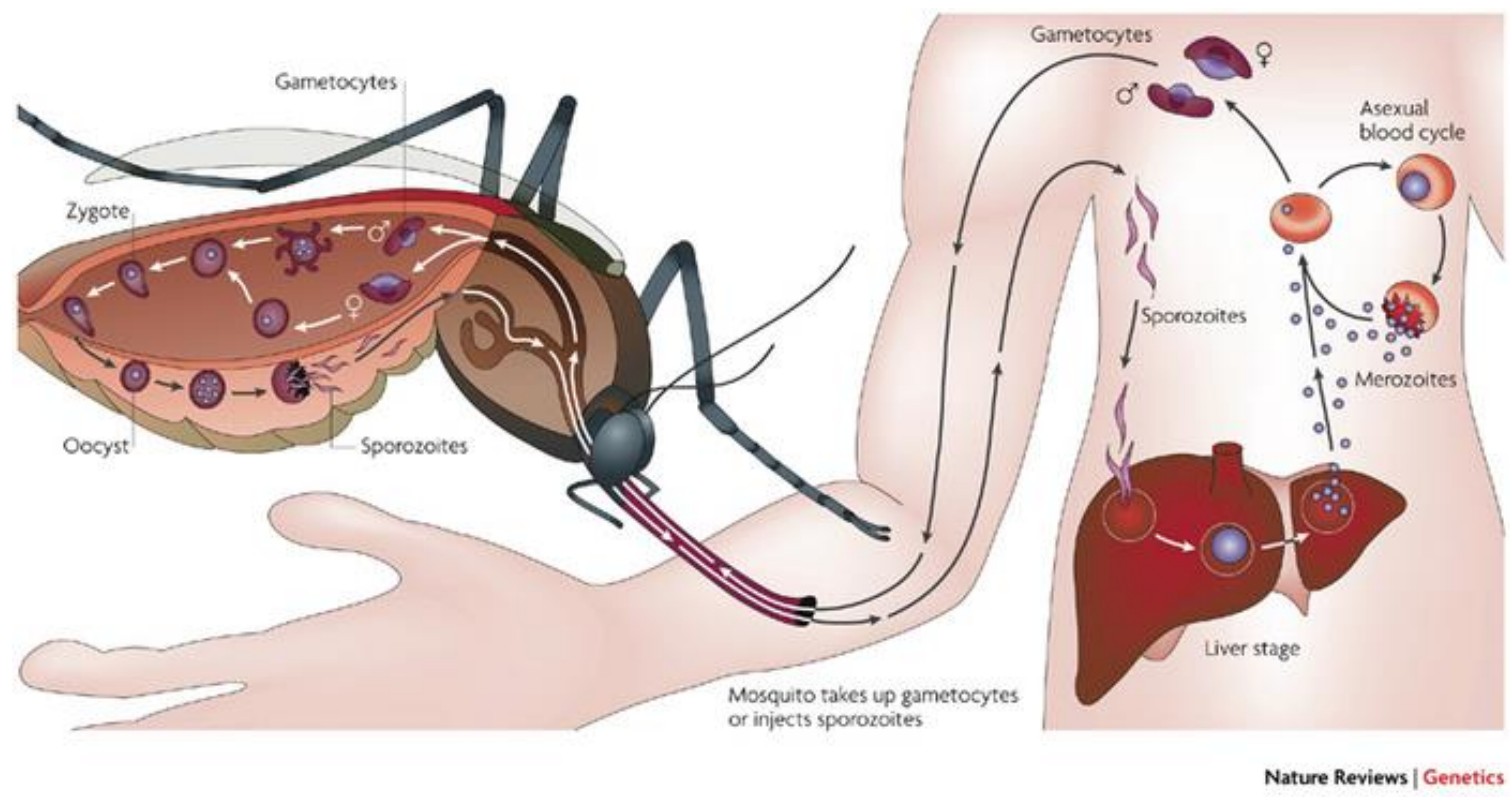

Figure 2: Lifecycle of Plasmodium falciparum. The lifecycle consists of human and malaria stages and each stage is antigenically distinct. Sexual reproduction occurs in the mosquito and asexual stages occur in humans. When a mosquito feeds on a host, it injects sporozoites that migrate to the liver and infect hepatocytes. After reproducing in hepatocytes to form schizonts, parasites emerge as merozoites and infect RBC. Most parasites undergo asexual reproduction, but a small fraction differentiate into male and female gametocytes. Gametocytes can be taken up by a mosquito during a blood meal and in the mosquito midgut they differentiate into gametes. Gametes fuse to form zygotes, which begin to invade the midgut wall and develop into oocysts. In the midgut wall, parasites multiply to form sporozoites which travel to the salivary glands where they are ready to initiate a new cycle of infection. 


\section{Malaria: host response}

Partial immunity to P. falciparum occurs in endemic areas following multiple infections. In areas of high transmission such as sub-Saharan Africa people develop almost complete protection from clinical disease by early adulthood. This delayed development of immunity leaves children and pregnant women at greatest risk for complicated disease (Langhorne et al. 2008). Immunity to severe clinical disease requires persistent stimulation by parasite antigens, wanes when individuals leave endemic areas and does not develop in areas of low transmission (Gupta et al. 1999). Natural malaria infections suppress B cell memory development, which leads to short lived antibody responses after infection, and P. falciparum induces expression of CD4+ T cell inhibitory factors (Hviid 2007, Kinyanjui et al. 2009, Anders 1986, Butler et al. 2012)

Lifecycle stages are antigenically distinct from each other and immunity to one stage does not provide protection from other stages. Naturally acquired immune responses to malaria are mostly directed against blood stages including merozoites as well as intra-erythrocyte stages. Based on passive transfer experiments, antibodies are the major component of this protection and are involved in blocking merozoite invasion of RBC, antibody dependent cellular killing and surface bound antibodies leading to increased clearance of infected RBC (Blackman et al. 1990, Bouharoun-Tayoun et al. 1995 and Bull et al. 1998).

Host immune responses also play a role in the pathology associated with malaria. TNF is protective (Taverne 1987) but high levels of TNF and other proinflammatory cytokines are associated with severe disease (Ochiel et al. 2005). IL-10 dysregulation also 
plays a role and low IL-10 responses are associated with severe anemia, while abnormally high IL-10 responses are associated with respiratory distress (Kurtzhals et al. 1998, Awandare et al. 2006).

\section{Malaria: current treatments}

Treatment of malaria depends on a variety of factors including species, prior exposure, severity of disease and geographic location. Naïve patients are often hospitalized, whereas partially immune patients don't always require hospitalization. During treatment, parasitemia is monitored using daily blood smears.

One of the major disadvantages of early synthetic anti-malarial drugs is that they only target erythrocytic stages, which are the most abundant and metabolically active. High parasite density and high mutation rates due to rapid metabolic activity increase the likelihood of drug resistance among erythrocytic stages compared to other life cycle stages that are less abundant and mutation prone (Fidock 2013). Drugs that only inhibit erythrocytic stages may not effectively inhibit transmission to mosquitoes by blocking asexual forms of P. falciparum, allowing the life cycle to continue (Leroy et al. 2014).

Chloroquine was the first mass produced drug for malaria treatment and prevention and is effective against all blood stages, additionally, it is well tolerated if administered orally (White 1996, Taylor and White 2004). Although chloroquine is still used to treat other forms of malaria, P. falciparum has developed widespread resistance, and chloroquine often cannot be used to treat falciparum malaria.

The WHO recommends oral artemisinin combination therapy (ACT) as the first line treatment for uncomplicated falciparum malaria due to efficacy against all asexual 
stages of the parasite lifecycle as well as gametocytes and minimal side effects. A second drug is administered with artemisinin derivatives to reduce resistance. Severe falciparum malaria is treated with i.v. administration of artemisinin or quinine. Artemisinins are preferable due to broader targeting of parasite life cycle stages and a more favorable side effect profile (ter Kuile et al. 1993).

Drug resistance varies between regions and should be considered when selecting therapy. Artemisinin resistance has been noted in areas where monotherapy was applied instead of using ACT (Das et al. 2013). Artemisinin resistance is particularly concerning because of the drug's efficacy against multiple lifecycle stages and ability to block transmission by also targeting gametocytes. Quinine is used in areas where resistance to other drugs may be a problem but is not the preferred treatment due to severe side effects and bitter taste, which reduces compliance. Resistance has been documented for all currently used antimalarials and this threat has accelerated the need to develop newer methods of treatment and prevention (Leroy et al. 2014).

\section{Malaria: approaches to eradication}

After World War II, DDT and chloroquine were first implemented, which led to decreased global distribution of Plasmodium falciparum and P. vivax. By the 1960's it became apparent that insecticides and mass drug administration would not be sufficient to completely eliminate malaria (Dobson et al. 2000). This led to decreased interest in continuing mass eradication efforts and a resurgence in incidence and mortality (Cohen et al. 2012). The malaria epidemic in the 1990s in Africa (Snow et al. 2012) resulted in the development of a new elimination strategy in 2000 called the Roll Back Malaria Global 
Action Plan (GMAP). Newer efforts have taken into account the heterogeneity of Plasmodium spp. and focused on interrupting transmission instead of just control (Alonso et al. 2011). Unlike previous efforts, which often bypassed local health systems, recent efforts have focused on long term solutions by integrating malaria control efforts into local health systems (Alonso et al. 2011).

Vector control is an important aspect of the malaria eradication program and methods such as insecticide treated nets (ITN) are particularly effective because they kill vectors before they become infectious, a process that takes several days after ingesting Plasmodium spp. (Enayati and Hemingway 2010). Use of insecticide treated nets has been widespread since 2006 but transmission rates remain high and mathematical models show that ITNs might not be adequate to reduce transmission in highly endemic areas (Noor et al. 2014, Griffin et al. 2010, Smith et al. 2009). In addition to drug resistance in parasites, mosquitoes have been developing resistance to insecticides, which requires developing new insecticides to maintain efficacy (Ranson et al. 2009). Additionally, not all vectors feed indoors and therefore may not be susceptible to ITN. As an alternative approach, genetic control programs have been proposed to reduce natural populations of these vectors (malERA 2011, Terenius et al. 2008 and Sinkins and Gould 2006).

New approaches to developing antimalarials have focused on targeting multiple life cycle stages to eliminate parasites and according to the Medicines for Malaria Venture should cure disease by rapidly clearing parasites from the blood, target liver stages and block transmission by targeting asexual blood stages and be effective in a single dose (Leroy et al. 2014). 
Targeting hepatic stages would have the advantage of preventing infection by blocking the first stage of the parasites lifecycle in humans and would prevent transmission by preventing formation of gametocytes, additionally, the low density of parasites during hepatic stages would reduce the likelihood of resistance compared to drugs that target erythrocytic stages (Lindner et al. 2012). Unfortunately, studying liver stages is difficult due to the low parasite load and no efficient high throughput liver stage drug screens exist (Leroy et al. 2014).

Blocking parasite transmission is considered critical for eradication of malaria (Sinden et al. 2012). Therapies that block transmission should target gametocyte formation to prevent sexual stages from being ingested by mosquitoes. Several drugs to target sexual stages have been identified, including primaquine, which is in clinical use (White et al. 2012, Tanaka et al. 2013). The current method for assessing transmission blocking activity is the standard membrane feeding assay, where mosquitoes are fed serum containing gametocytes and candidate drugs and progression to oocysts is determined (Leroy et al. 2014).

\section{Malaria: vaccine development}

Vaccines are an important component of the malaria eradication plan and would be especially beneficial for children in highly endemic countries who have not yet developed immunity (Alonso 2011). Evidence of resistance to clinical disease after multiple exposures and the ability of transferred $\operatorname{IgG}$ to protect naïve humans against disease indicate that a vaccine against malaria is possible and that antibodies can reduce disease (Schwartz et al. 2011). However, these responses are transient and prevent 
clinical disease but do not completely prevent infection in endemic settings (Schwartz et al. 2011). The major challenge to developing a vaccine for P. falciparum are its multiple antigenically distinct lifecycle stages with several amplification phases. Natural immunity is not well understood at the molecular level and few target antigens have been identified (Moorthy and Kieny 2010).

According to the malaria eradication agenda developed in 2009-2010, effective eradication of malaria requires a focus on preventing transmission more than preventing morbidity (Schwartz et al. 2011). This includes vaccines that target pre-erythrocytic stages and therefore provide sterilizing immunity as well as vaccines that target sexual stages and mosquito antigens. However, the latter two have received the least amount of attention (Schwartz et al. 2011). Transmission blocking vaccines (TBV) target sexual and mosquito stages of P. falciparum (malERA 2011). The broader category of vaccines that interrupt transmission also includes vaccines against mosquito proteins that are essential for parasite development and highly effective erythrocyte vaccines that would also effectively prevent transmission (Alonso 2011).

Naturally acquired immunity to P. falciparum may not be due to immune responses to pre-erythrocytic stages but immunization with pre-erythrocytic targets can induce protective immunity. This indicates that the immunity generated by preerythrocytic vaccines would not mimic natural immunity but it may be more effective (malERA 2011). Pre-erythrocytic stage vaccines would prevent sporozoite invasion of hepatocytes or activate cellular immune responses to kill infected hepatocytes. If completely effective, this would eliminate parasites before they could infect erythrocytes 
and prevent both disease and transmission. Even a partial reduction in parasites that leave the liver would reduce the severity of disease and could allow more time for the infected host to develop responses against later stages (Schwartz et al. 2011).

Irradiated sporozoites inoculated by mosquito bite prevent infection upon experimental challenge, but this requires hundreds of bites and is transient (Cochrane et al. 1980, Clyde et al. 1973). Similar results were found using purified irradiated sporozoites, where high doses were required and did not provide adequate protection (Epstein et al. 2011, Daubenberger 2011). Another approach to induce immunity using whole parasites is chloroquine controlled infection, where infected mosquitoes bite people in the presence of chloroquine. This results in high levels of effector memory, less suppression of T cells and only requires 10-15 bites (Butler et al. 2012, Roestenberg et al. 2011). However, drug resistance would reduce the utility of this approach (Schuldt and Amalfitano 2012). Additionally, storing whole sporozoites presents a challenge for using a sporozoite based vaccine in the field (Epstein et al. 2011).

The most successful malaria vaccine candidate has been RTS,S produced by GSK and the PATH Malaria Vaccine Initiative. RTS,S is $80 \%$ effective, has completed Phase 3 clinical trials and may receive WHO approval by the end of 2015. RTS,S is directed against the circumsporozoite protein, which is the most abundant surface antigen on sporozoites and liver stages and the vaccine can induce antibody and CD4+ T cell immunity. RTS,S is a fusion between CSP and hepatitis B surface antigen. In an effort to develop CD8+ responses to CSP, clinical trials are ongoing to boost immunize RTS,S immunized individuals with Ad35 encoding CSP (WHO 2010). Attempts to develop a 
pre-erythrocytic vaccine using whole parasite have not been successful due to the large numbers of parasites needed for efficacy and stability concerns (Schwartz et al. 2011).

Although naturally acquired immunity appears to be primarily due to targeting blood stages, developing a broadly effective blood stage vaccine is difficult due to antigenic polymorphism (Colling and Jeffery 1999). Merozoite surface protein 1 is a well characterized protein used by merozoites for invasion and antibodies against MSP-1 reduce clinical malaria (Holder 2009, Fowkes et al. 2010). All studies use portions of MSP-1 due to its large size, which makes identification of critical epitopes important. Results using MSP-1 have been mixed due to allelic variation in the protein and have shown high immunogenicity but strain specific responses (Ogutu et al. 2009). Antibody titers to MSP3 have the most consistent association with protection from clinical malaria (Fowkes et al. 2010). Synthetic MSP3 peptide generates high antibody titers, but only in naïve individuals (Audran et al. 2005, Sirima et al. 2007, Nebie et al. 2009). Apical Membrane Antigen 1 is expressed on merozoites, sporozoites and hepatic stages and antibodies to AMA1 are major component of natural immunity (Courtin et al. 2009, Udhayakumar et al. 2001). However, AMA1 is highly polymorphic and developing a successful AMA1 vaccine would need to overcome this (Takala and Plowe 2009).

\section{Malaria: transmission blocking vaccines}

The importance of TBV has increased as a result of poor efficacy of most blood stage vaccine candidates in trials and the emphasis on reducing transmission as a means to eradicate malaria (Schwartz et al. 2011). Transmission blocking vaccines can target sexual stages of Plasmodium or mosquito vector antigens. Currently most sexual stage 
vaccine projects are in preclinical stages (Schwartz et al. 2011). As of 2012, 24 proteins have been identified as targets of transmission blocking antibodies. There are four lead candidates: Pfs48/45 and Pfs230 are present on gametes and gametocytes and Pfs25 and Pfs28 are present on ookinetes (Sinden et al. 2012). The mosquito protein APN1 has also been the focus of some studies.

One particular challenge for developing a TBV is that unlike blood stage or preerythrocytic vaccines, a TBV would act at the community level rather than the individual level (Nunes et al 2014). However, over time this would translate to individual benefit by reducing disease in communities where vaccine recipients live and reduce the risk of reinfection (PATH 2010). Additionally, primaquine is sometimes administered to infected patients to prevent transmission with no expectation of clinical benefit to the patient (WHO, Eziefula et al. 2014). Preliminary assessments of community acceptance of TBV shows that people in affected communities are open to these interventions (Bingham et al. 2012, Ojakaa et al. 2011).

\section{Pfs25}

Pfs25 is the most studied sexual stage antigen. It is present primarily on ookinetes and is involved in invasion of the midgut wall. Anti Pfs25 antibody titers consistently correlate with transmission blocking activity by SMFA (Vuola et al. 2005). In this approach, a mosquito that feeds on an infected individual who has been immunized will take up gametocytes as well as anti-Pfs25. When Pfs25 is expressed in the mosquito midgut, antibodies bind to Pfs 25 and block invasion of the midgut wall. Compared to other sexual stage antigens, serum from mice immunized with Pfs 25 contains similar 
levels of sexual stage antigen specific antibody titers but is significantly more effective at blocking transmission (Miura et al. 2013).

Pfs25 administered with aluminum hydroxide (alum) as an adjuvant generates low antibody titers in mice and must be administered multiple times to block parasite transmission (Kubler-Kielb et al. 2006). Using various adjuvants, researchers have tried to improve the immunogenicity of Pfs 25 . A clinical study using Pfs 25 adjuvanted with Montanide ISA 51 was discontinued due to low levels of antibody titers and adjuvant toxicity (Wu et al. 2008). A Pfs25 Pseudomonas aeruginosa ExoProtein A (EPA) conjugate with alum as an adjuvant has shown induction of high antibody titers and transmission blocking activity but this requires 3 injections (Qian et al. 2008, Qian et al. 2007). Viral vectored approaches have also been investigated for Pfs 25 immunization and a heterologous prime-boost with Ad5 and MVA induces a strong transmission blocking antibody response (Goodman et al. 2011). Cholera toxin and Neisseria menigitides outer membrane protein have also been investigated as adjuvants for Pfs25 (Arakawa et al. 2005 and Wu et al. 2006).

\section{Pfs25: Structure}

Pfs 25 is a $25 \mathrm{kDa}$ protein composed of 4 epidermal growth factor (EGF) like domains. It is expressed on the surface of ookinetes. The $\mathrm{N}$ terminal portion contains a membrane secretion signal sequence and the $\mathrm{C}$ terminal portion has a GPI anchor sequence. Pfs 25 is a cysteine rich protein and contains 11 disulfide bonds (Kaslow et al.1988 and Saxena et al. 2006). The protein has multiple surface exposed loops, which 
are most prominent in EGF-like domain 2 and 3 and contain the most likely predicted B cell epitopes (Figure 1).

Pfs 25 has been expressed in a variety of systems such as yeast, cell free translation in wheat germ, plants and algae (Barr et al. 1991, Kaslow and Shiloach 1994, Tsuboi et al. 2008, Farrance et al. 2011 and Gregory et al. 2012). Proper folding of Pfs25 in ectopic expression systems is difficult due to its complex structure. Yeast expressed Pfs 25 consists of two isoforms, which could reduce the efficacy of immunization with this recombinant protein (Tsai et al. 2006 and Kubler-Kielb et al. 2007). Expression in E. coli is complicated by ineffective formation of disulfide bonds in bacterial cells. All 11 disulfide bonds in Pfs25 are necessary for proper folding and misfolded proteins must be solubilized and refolded to generate the appropriate arrangement of disulfide bonds (Kaslow et al. 1994). A successful purification and refolding of Pfs25 in the correct conformation has been described by Kumar et al. 2014.

The cytoplasm in E. coli may contain proteases that could interfere with protein isolation and to address this strains such as BL21 have been developed, which lack ompT and lon proteases. Recombinant proteins expressed in E. coli often do not fold properly and require additional steps to refold them. Folding of disulfide bond containing proteins is particularly error prone in E. coli because of the reducing environment in the cytoplasm, which prevents disulfide bond formation (Sorensen and Mortensen 2005). The advantages of E. coli are that it is a well characterized expression system and high yields of protein can be collected from bacterial cultures. Despite the limitations on expressing 
correctly folded disulfide bond containing proteins, multiple EGF like proteins have been refolded in vitro after expression in E. coli, including Pfs25. 


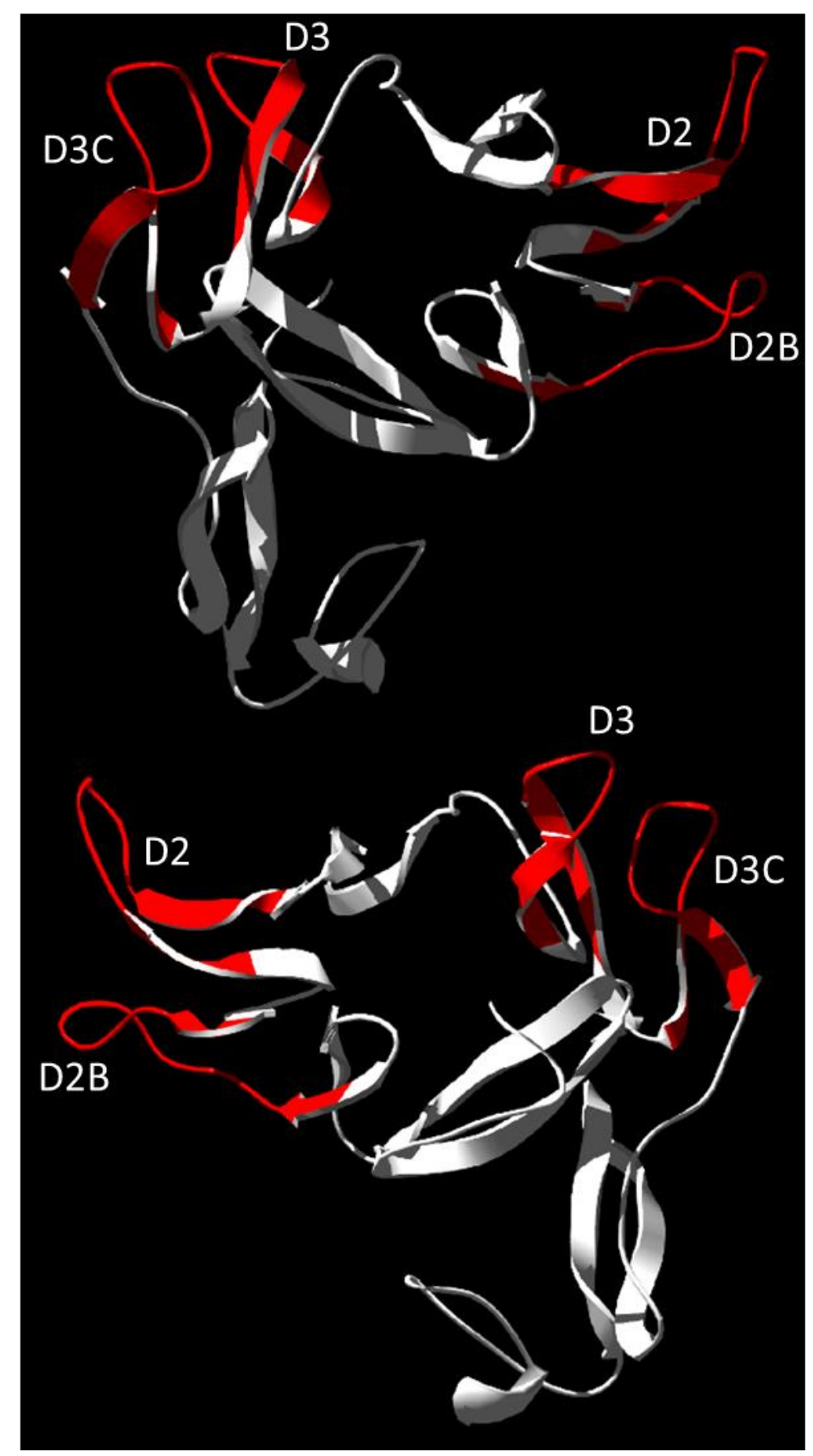

Figure 3: Structure of Pfs25 modeled on the crystal structure solved for the related sexual stage antigen from Plasmodium vivax, Pvs25. Loops containing predicted B cell epitopes in domains 2 and 3 are highlighted in red. 


\section{Antibody response to vaccines}

After injection, antigen either diffuses to draining lymph nodes, or it can be internalized by DC at the site of injection and transported to lymph nodes. Proteins that encounter antigen specific naïve B cells bind to surface IgM and trigger a cascade that leads to formation of germinal centers where they proliferate and differentiate into plasma cells or memory B cells with help from APC and T cells.

Activated B cells can proceed down the extrafollicular pathway, which leads to a rapid but short lived and low affinity antibody response or they can form germinal centers leading to memory formation. The germinal center pathway is more important for vaccine efficacy. The germinal center pathway begins when activated B and T cells migrate to B cell follicles as a result of signaling by FDC. In follicles, B cells receive signals from FDC and T cells and proliferate. During proliferation, they undergo class switch proliferation and switch from IgM production to IgG, IgA or IgE. They also undergo affinity maturation. High affinity B cells display vaccine antigens in MHCII and are bound by antigen specific $\mathrm{T}_{\mathrm{FH}}$ cells, which provide costimulatory molecules and leads to proliferation of B cells and differentiation to memory B cells or plasma cells. This process requires 10-14 days before hypermutated IgG appears in serum (Flehmig et al. 1997).

The antibody response to antigen depends on several factors. Intrinsic antigenicity of proteins is the main determinant of antibody response and is highly variable (Siegrist 2011). Live vaccines elicit the strongest antibody responses because they are better at stimulating innate immune responses and non-live vaccines usually require at least two 
vaccine doses (Pashine et al. 2005, Cassidy et al. 2001, VanDerWielen et al. 2000). Host factors also play a role in vaccine efficacy and genetic variability can affect the antibody response (Newport et al. 2004). Antigen dose is an important consideration and lower doses favor production of memory cells, while higher doses favor production of plasma cells (Ahman et al. 1999).

The number of long lived plasma cells determines the duration of antibody secretion after immunization and becomes apparent after 6-12 months when the short lived plasma cell response wanes (Honorati et al. 1999, VanHerck et al. 2000). Long lived plasma cells form from GC plasma cells that migrate to the bone marrow as a result of signaling by bone marrow stromal cells (Minges Wols et al. 2002). Although the exact mechanism for LLPC formation and persistence is unknown, only live attenuated viral vaccines can induce antibody titers that persist for decades without requiring boost immunization (Manz et al. 2005). Memory B cells do not secrete antibody, therefore they are not protective unless they are stimulated by antigen to differentiate into plasma cells. However, antigen stimulation of memory B cells, such as during boost immunization, drives proliferation into plasma cells with higher affinity antibodies than those generated by primary immunization (McHeyzer-Williams and McHeyzer-Williams 2005).

In the context of TBV, persistent antibody secretion is necessary as Pfs 25 is not expressed in human stages and a previously immunized infected person would not be reexposed to antigen. As a result, low dose primary immunization to elicit a high memory response followed by a high dose boost immunization to elicit high levels of high affinity 
plasma cells would be an effective strategy that could generate more LLPC and persistent antibody titers.

\section{Vaccine Adjuvants}

Adjuvants are compounds that enhance the immune response against a coadministered target antigen (Petrovsky and Aguilar 2004). Despite adjuvants being used in vaccines since the 1920's, few adjuvants are licensed for clinical use due to limited knowledge of mechanisms of action (De Gregorio et al. 2013). Since adjuvants are used to improve immune responses, they may also be associated with toxicity due to overactivation of immune pathways and the balance of potency and toxicity is an important consideration when developing adjuvants (Petrovsky and Aguilar 2004).

Aluminum salts (alum) were one of the first adjuvants used, with published reports of alum as early as 1926 (Glenny et al. 1926). Alum adjuvants are used in multiple vaccines including diphtheria, tetanus, pertussis, hepatitis A and B and anthrax (DeGregorio et al. 2013). When formulated with alum, antigens are adsorbed to the adjuvant, which can increase antigen stability and increases uptake of antigen by APC (Hem and White 1995, Flach et al. 2011). Alum also increases activation of DC and other immune effector cells (Sokolovska et al. 2007, Kool et al. 2008, Seubert et al. 2008). Alum activates the NLRP3 inflammasome, which is required for its adjuvant effect, but does not signal through TLR (Gavin et al. 2006, Eisenbarth et al. 2008, Kool et al. 2008). Additionally, alum induces release of DAMP's such as uric acid and dsDNA, which contributes to its pro-inflammatory effect (Kool et al. 2008, McKee et al. 2013, Marichal et al. 2011). 
Freund's complete adjuvant is an emulsion of water, mineral oil and killed mycobacteria and is the gold standard adjuvant, although it is too toxic for human use due to severe local reactions (Freund et al. 1937, Petrovsky and Aguilar 2004). Oil-in water emulsion adjuvants such as MF59 and AS03 are used in influenza vaccines. These adjuvants are a mix of squalene and surfactants with uniform sized 160nm particles (DeGregorio et al. 2013). MF59 does not directly activate monocytes but it stimulates them to produce chemokines and promotes antigen uptake by APC (Dupuis et al. 2001). Unlike alum, MF50 does not activate the Nlrp3 inflammasome (Seubert et al. 2011). AS03 also triggers innate responses in draining lymph nodes due to the presence of alpha-tocopherol (Garcon et al. 2012).

TLR agonists are a broad class of adjuvants that target PRR of the innate immune system and include dsRNA, ssRNA, CpG motifs, lipids, lipopeptides, bacterial cell wall components and flagellin (De Gregorio et al. 2013). TLR4 agonists such as MPL mimic the activity of LPS and are found in hepatitis B and HPV vaccines (Casella and Mitchell 2008). TLR4 agonists enhance antibody responses and Th1 helper T cell responses (Didierlaurent et al. 2009). TLR9 is found on endosomes and recognizes DNA containing CpG, which is usually found in bacteria. TLR9 agonists can elicit different immune responses depending on the type of CpG motifs (Vollmer et al. 2004). Bacterial flagellin is recognized by TLR5. Since flagellin is a protein, it can be used to create fusion proteins with target antigen (Taylor et al. 2011). Flagellin has been successfully used in multiple vaccines to induce strong humoral responses and can increase transport and retention of antigen in lymph nodes (Sixt et al. 2005). The effects of flagellin are most 
likely mediated by $\mathrm{T}$ cells and DC and it does not appear to signal directly through B cells (Mizel and Bates 2010). Viral RNA or synthetic RNA mimics stimulate TLR7 and TLR8 on endosomes (Akira and Hemmi 2003). TLR3 recognizes dsRNA and is the target of adjuvants such as Poly(I:C) (Jasani et al. 2009).

Viral vectors have also been investigated as adjuvants because of their strong ability to stimulate innate and adaptive immune responses. In particular adenovirus has been shown to trigger strong adaptive immune responses to antigens from multiple pathogens. Ad vectors can deliver large transgenes and can also accommodate antigenic epitopes in their capsid.

\section{Adenovirus}

Adenoviruses are non-enveloped double stranded DNA viruses. Their $34-43 \mathrm{~kb}$ genome is small enough to enable easy manipulation and large parts of the genome can be replaced. Ad are divided into serotypes based on antibody neutralization and six subgroups based on sequence homology and red blood cell agglutination (Tatsis and Ertl 2004). Ad5, of subgroup C, is the most commonly studied of at least 52 human serotypes of Ad (Schuldt and Amalfitano 2012).

The Ad genome is divided into early and late genes based on their expression. E1A is involved in activation of other viral genes, therefore deleting this gene results in replication defective virus and can be replaced with a transgene for expression by recombinant virus (Anderson et al. 2000, He et al. 1998). The E3 gene product allows Ad to persist in lymphoid cells after acute infection and is also often removed (Tatsis and Ertl 2004). 
In immunocompetent hosts, human Ad cause mild upper respiratory or gastrointestinal disease. The surface exposed portion of hexon, the major capsid protein, contains flexible loops that are variable between serotypes and are the target of neutralizing antibodies (Tatsis and Ertl 2004). Neutralizing antibody titers to common serotypes such as Ad5 can be detected in up to $80 \%$ of some adult populatitons, indicating prior infection in these individuals (Tatsis and Ertl 2004). Ad potently activate the innate and adaptive immune responses. By expressing PAMPs, they stimulate production of cytokines and differentiation of antigen presenting cells (Tatsis and Ertl 2004).

\section{Adenovirus vaccine vectors}

Adenoviral vectors were originally proposed as gene therapy vectors, however, adaptive and innate immune responses to these vectors limited their utility for gene therapy. Ad vectors are useful as vaccine adjuvants for multiple reasons, including ease of propagation, mild disease in immunocompetent hosts and broad tropism (Tatsis and Ertl 2004). Although multiple viral vectors have been considered for use in malaria vaccines, only Ad and MVA have made it to clinical trials (Schuldt and Amalfitano 2012).

Ad have been useful as vaccine vectors due to their ability to stimulate humoral and adaptive immune responses, which is partly due to stimulation of multiple innate immune responses by capsid and genome (Appledorn et al. 2008a,b, Hartman et al. 2008, Barlan et al. 2011). Ad vectors have been successfully used to generate adaptive 
responses against antigens from rabies, cancer, HIV and malaria (Gabitzsch et al. 2009, Xiang et al. 1996, Shott et al. 2008, Naslund et al. 2007).

Compared to other adjuvants, Ad vector approaches can promote stronger antigen specific adaptive immune responses, including to malaria antigens (Rodrigues et al. 1997, Shott et al. 2008, Bruna-Romero et al. 2004, Bruder et al. 2010). Ad expressing CSP can induce equivalent antibody titers and an equivalent cellular response as RTS,S/AS01B and does not require additional adjuvants (Shott et al. 2008). Importantly Ad based malaria vaccines induce $\mathrm{CD} 8+\mathrm{T}$ cell responses, which are important for protection against pre-erythrocytic stages (Rodrigues et al. 1997, Rodrigues et al. 1998, BrunaRomero et al. 2008). Ad vectors have also been used to increase antibody titers to blood stage malaria antigens. Ad expressing AMA-1 or APA-1 induces antibody titers equivalent to recombinant protein with adjuvant (Bruder et al. 2010).

Limitations of Ad vectors include neutralizing antibodies to vectors due to preexisting immunity or homologous primary immunization. In human trials using primeboost with Ad expressing CSP and AMA-1, boost immunization was less immunogenic than primary immunization and prime-boost did not protect against malaria challenge (Tamminga et al. 2011, Sedagh et al. 2011). Pre-existing immunity to Ad5 is a concern in Sub-Saharan Africa where over $50 \%$ of individuals have neutralizing antibody titers to Ad5, which would weaken immune responses to Ad5 vectored antigens (Barouch et al. 2011, McCoy et al. 2007). To overcome this limitation, alternative Ad serotypes can be used (Limbach and Richie 2009). Ad35 based CSP vaccines induce equivalent T and B cell responses to CSP as Ad5 vectors and RTS,S/AS01B (Shott et al. 2008). Chimpanzee 
Ad should have the lowest levels of pre-existing immunity in human populations and these vectors are also being investigated as alternatives to Ad5 (Reyes-Sandoval et al. 2008). Immunization with ChAd63 expressing Pfs 25 followed by MVA expressing Pfs 25 is as effective as Ad5/MVA prime-boost (Goodman et al. 2011).

\section{Improving Ad vectors for TBV}

My goal is to evaluate how immunization with different Ad vectors affects the antibody response to EGF-like domains in Pfs 25 and identify portions of the protein that are highly associated with transmission blocking. To do this I will first purify EGF-like domains from Pfs 25 and use ELISA to assess domain specific titers in virus from mice immunized with Ad vectors expressing Pfs25 or displaying epitopes from Pfs25. Using epitope prediction tools, I will also develop new vectors with capsid displayed epitopes to focus the antibody response to multiple highly immunogenic epitopes that are the target of transmission blocking antibodies during infection. Finally, I will use Ad with capsid displayed FliC to determine if I can improve the ability of our vectors to stimulate antibody responses.

The results of this work will provide new information about how Ad vectors induce antibody responses to target antigens. I will also have a better understanding of how Ad vectors with capsid displayed epitopes can be used to focus antibody responses to functionally relevant epitopes. Using FliC, I will learn how capsid modifications target the adaptive immune response to antibody production. 


\section{CHAPTER TWO}

\section{MATERIALS AND METHODS}

\section{Cell Lines and Cell Culture}

Our lab obtained HeLa and 293Trex cells from ATCC. We received $293 \beta 5$ cells from Glen Nemerow. We used HyClone tissue culture reagents. We maintained HeLa, $293 \beta 5$ and 293Trex cells in Dulbecco Modified Eagle Medium (DMEM) with addition of $1 \mathrm{mg} / \mathrm{mL}$ streptomycin, $100 \mathrm{IU} / \mathrm{mL}$ penicillin, $0.25 \mathrm{mg} / \mathrm{mL}$ amphotericin $\mathrm{B}$, non-essential amino acids, $2 \mathrm{mM}$ glutamine, 10mM HEPES buffer and $1 \mathrm{mM}$ sodium pyruvate. We maintained 293Trex cells with $5 \mu \mathrm{g} / \mathrm{mL}$ blasticidin from Sigma Aldrich.

\section{Recombinant Virus Construction}

We generated Ad5gfp as described by Wodrich et al. 2010. To generate Ad5Pfs25 and Ad5Pfs25exo we used a version of the AdEasy system described by He et al. 1998 and Luo et al. 2007. Using this system we inserted a shuttle vector containing the Pfs 25 or Pfs25exo gene into an E1/E3 deleted Ad5 genome. We generated the Pfs25 gene using Genescript and codon optimized it for expression in humans. To generate Pfs25exo, we generated the codon optimized sequence for Pfs 25 and removed the $\mathrm{C}$ terminal transmembrane domain. To suppress Pfs25 and Pfs25exo expression during virus propagation, we inserted the tet operator (TO) from pcDNA4/TO/mycHisA upstream of the CMV promoter and propagated virus in 293Trex cells, which constitutively express the Tet repressor (TetR). In this system, TetR binds TO and blocks transcription of the Pfs25 or Pfs25exo transgene. Pfs25 expression prevents efficient recovery of virus 
because we found that Pfs 25 expression decreased viral yields more than 10 -fold. To confirm that Pfs25exo expression is suppressed in 293Trex cells, we used IFA with Pfs25 antiserum. To confirm that Pfs25exo is expressed by our construct, we used IFA with 293 cells stained with Pfs25 antiserum.

I identified predicted B cell epitopes from Pfs25 using the ElliPro tool (http://tools.immuneepitope.org/ellipro/). We generated $\mathrm{Ad}_{\mathrm{CD}}$ using galK recombineering as described by Warming et al. 2005. We created primers with the galK sequence flanked by sequences homologous to regions to either side of the insert site in HVR1 or HVR5 and used these primers to amplify galK from a plasmid (pgalK), which our lab obtained from the NCI BRB Preclinical Repository (NCI-FCRDC). Using homologous recombination, we replaced target sites in HVR5 with galK and used positive selection on minimal media plates with galactose to select successful recombinants. To replace galK with sequences from Pfs 25 we used homologous recombination with Pfs 25 sequences flanked by sequences homologous to the regions to either side of galK, which we generated as gBlocks from IDT-DNA. To identify successful recombinants we used negative selection on minimal media plates containing X-gal, which is converted to toxic metabolites by cells that have retained galK. To confirm correct inserts, we used PCR amplification of the hexon region and sequencing.

\section{Virus Purification and Titering}

We used 293Trex cells to propagate Ad5Pfs25exo and $293 \beta 5$ cells to propagate Ad $_{\mathrm{CD}}$. After propagation, we purified virus using two rounds of cesium chloride 
centrifugation and dialysed virus in $40 \mathrm{mM}$ Tris, $150 \mathrm{mM} \mathrm{NaCl}, 10 \%$ glycerol and $1 \mathrm{mM}$ $\mathrm{MgCl}_{2}$ (pH 8.2) (Wiethoff et al. 2005). We determined virus concentration by Bradford, where $1 \mathrm{mg}$ protein corresponds to $4 \times 10^{9}$ viral particles (Bio-Rad Laboratories, Inc.), froze aliquots in liquid nitrogen and stored them at $-80^{\circ} \mathrm{C}$. To determine viral titers of Ad $_{\mathrm{CD}}$, we serially diluted virus on HeLa cells and used flow cytometry to quantify GFP expression. To determine titers of Ad5Pfs25 and Ad5Pfs25exo, we serially diluted virus on HeLa cells and used IFA to detect hexon. To confirm expression of Pfs 25 exo, we used IFA with Pfs25 anti-serum after treating cells with GolgiStop for 4 hours to prevent protein secretion.

\section{Reagents and Antibodies}

For ELISA, we purchased 5x assay diluent (cat \# 00-4202-56) and 1xTMB substrate from eBioscience (cat \# 00-4201-56). For detection of primary mouse antibody we used HRP conjugated anti-mouse IgG from Abcam (ab97265). For protein purification we used TALON Metal Affinity Resin from Clontech (cat \# 635501). We obtained the anti-Pfs25 antibodies from Kim Williamson (conformation specific: ID2, conformation independent: 4B7).

\section{ELISA}

We coated high binding ELISA plates (Costar cat\# 07-200-35) with Pfs25 or purified domains from Pfs 25 at $1 \mu \mathrm{g} / \mathrm{ml}$ in coating buffer (Sodium Bicarbonate, $\mathrm{pH} 10$ ) shaking overnight at $4^{\circ} \mathrm{C}$. The next day we washed plates 4 times with $200 \mu \mathrm{l} /$ well $1 \mathrm{X}$ PBST (0.05\% Tween) and blocked with 200 $\mu 1 /$ well 1x AD (eBioscience 00-4202-56) for 
1 hour. We washed the plates four times and added $100 \mu 1 /$ well of serially diluted mouse serum or monoclonal anti-Pfs 25 antibody in $1 \mathrm{x}$ AD to plates for 2 hours. After 4 washes we added a $100 \mu \mathrm{l} /$ well of secondary anti-mouse IgG diluted 1:2000 in 1x AD for 1 hour. We washed plates 4 times and developed them using 50 $\mu \mathrm{l} /$ well 1x TMB substrate. After color change, we stopped the reaction with $25 \mu \mathrm{l} /$ well $1 \mathrm{M}$ sulfuric acid. We read plates with a KC Junior plate reader at an optical density of 450nm. We determined endpoint antibody titers (measured in ELISA units) using a dilution curve.

\section{Mice and Immunizations}

We used C57BL/6 mice (Jackson Laboratories cat\# 000663) for all experiments. The Institutional Animal Care and Use Committee of Loyola University Chicago (Maywood, IL) reviewed all studies. We immunized mice at 6-12 weeks old by injection in the left quadriceps. For primary immunization we immunized mice at 6-8 weeks of age and euthanized mice and collected serum by cardiac puncture after 21 days. For boost immunization experiments, we boost immunized 21 days after primary immunization and euthanized mice after 21 days and collected serum by cardiac puncture. We used a volume of $50 \mu \mathrm{L}$ for all injections.

For immunizations with Pfs 25 protein, we used yeast produced Pfs 25 from the $\mathrm{NIH}$ adsorbed to aluminum hydroxide (alum) purchased as Alhydrogel (Invivogen cat\# 21645-51-2). To prepare protein-alum for injection, we added $25 \mu \mathrm{L}$ alum to $2.5 \mu \mathrm{g}$ Pfs 25 in a total volume of $50 \mu \mathrm{L}$. For all primary immunizations with virus we used $10^{9}$ viral particles. For secondary immunization with $\mathrm{Ad}_{\mathrm{CD}}$ we used $10^{10}$ viral particles. 
We collected blood from euthanized mice by cardiac puncture. To isolate serum, we kept blood on ice for 1-4 hours and spun down red blood cells at 8000rpm for 5 minutes. We aliquoted supernatants, froze them in liquid nitrogen and stored them at $80^{\circ} \mathrm{C}$.

\section{Pfs25 Domain Synthesis and Purification}

We used a previously developed codon optimized Pfs25 sequence to select sequences encoding Pfs25 domains 1-4. For domain 4, we selected the sequence without the transmembrane domain. For domain 1 we removed the membrane secretion signal sequence. We ordered the domain sequences as gBlocks from IDT-DNA and ligated them into the pGEMT-easy vector. We digested pGEMT-easy-Pfs25Dx with NdeI and BamHI to free the Pfs25 domain sequence and ligated this fragment into protein expression vector $\mathrm{pET} 15 \mathrm{~b}$ that had been digested with NdeI and BamHI. We confirmed ligation by digesting pET15bPfs25Dx with NdeI and BamHI and using gel electrophoresis to identify bands corresponding to the Dx sequences.

To express Pfs25D1-4 we transformed BL21 E. coli, which are optimized for protein expression and grew cultures overnight in $\mathrm{LB}$ with ampicillin at $37^{\circ} \mathrm{C}$. The next day we diluted overnight cultures 1:20 in 500mL LB with ampicillin and grew them at $37^{\circ} \mathrm{C}$ until an $\mathrm{OD}_{600}$ of 0.6 . We induced protein expression using $1 \mathrm{mM}$ IPTG for $4 \mathrm{hrs}$. We harvested cells by centrifugation at $0^{\circ} \mathrm{C}$. We performed all subsequent steps on ice or at $0^{\circ} \mathrm{C}$. To lyse cells we incubated the cell pellet with $40 \mathrm{~mL} 1 \%$ triton $\mathrm{X}-100,0.5 \mathrm{mg} / \mathrm{mL}$ lysozyme and 1:100 DNase in 50mM PBS per liter of culture. To prevent protein 
degradation we added 1:100 PMSF to all buffers. We solubilized the pellets in lysis buffer and centrifuged lysate at $13,000 x \mathrm{x}$ for $15 \mathrm{~min}$. Due to presence of protein in lysate supernatant and reported presence in inclusion in bodies in pellet after lysis, we purified both soluble and insoluble fractions.

We purified Pfs25 domains present in inclusion bodies according to the Pfs 25 purification and refolding protocol developed by Kumar et al. 2014. To solubilize inclusion bodies and denature misfolded proteins, we incubated pellets from cell lysate in denaturation buffer $(100 \mathrm{mM}$ tris, $8 \mathrm{M}$ urea, $1 \% \mathrm{BME})$ at $4^{\circ} \mathrm{C}$ overnight. After solubilization, we loaded pellets onto $0.5 \mathrm{~mL}$ TALON cobalt resin columns. We loaded soluble Pfs 25 directly onto columns and incubated with denaturation buffer overnight to reduce misfolded disulfide bonds.

For on column refolding, we sequentially washed the column with $10 \mathrm{~mL}$ refolding buffer (100mM TrisCl, 500mM NaCl, $10 \%$ glycerol, $1 \mathrm{mM}$ imidazole, $0.5 \mathrm{mM}$ GSSG and 5mM GSH) containing decreasing amounts of urea from $8 \mathrm{M}$ to $0 \mathrm{M}$, incubating for $1 \mathrm{hr}$ at each step. To elute protein we used $150 \mathrm{mM}$ imidazole and dialyzed protein in a $3.5 \mathrm{kD}$ dialysis cassette in PBS with $1 \%$ glycerol.

To purify protein for refolding by dilution, we loaded supernatant from BL21 on $0.5 \mathrm{~mL}$ TALON cobalt resin columns. We washed columns once with $10 \mathrm{~mL}$ Wash Buffer 1 (50mM phosphate, 500mM NaCl, $1 \mathrm{mM}$ imidazole and $1 \%$ triton $\mathrm{X}-100)$ and with $10 \mathrm{~mL}$ Wash Buffer $2(50 \mathrm{mM}$ phosphate, $500 \mathrm{mM} \mathrm{NaCl}$ and $1 \mathrm{mM}$ imidazole) in 1 $\mathrm{mL}$ increments. To elute protein we used $150 \mathrm{mM}$ imidazole and dialyzed protein in a 
3.5kD dialysis cassette in PBS with $1 \%$ glycerol. We precipitated protein using trichloroacetic acid (dilute TCA to $10 \%$ in sample, precipitate overnight at $-20^{\circ}$, spin sample, wash with acetone and evaporate acetone) and resuspended precipitated protein in denaturation buffer. After resuspending protein in denaturation buffer to achieve a concentration of $2 \mu \mathrm{L}$, we diluted the solution $1: 20$ in $100 \mathrm{mM}$ tris with $0.5 \mathrm{mM}$ GSSG and 5mM GSH. After dilution, we dialyzed samples in $3.5 \mathrm{kD}$ dialysis cassettes in PBS with $1 \%$ glycerol.

We determined concentration of protein by Bradford in all cases and used tris tricine gel electrophoresis (10\% separating, 4\% stacking) followed by Coomassie stain to confirm sample purity and Western Blot with Pfs 25 anti-serum to confirm presence of Pfs25 domains. We used ELISA with conformation dependent antibody ID2 to assess refolding success for D3 and conformation independent antibody 4B7 to confirm that peptide is $\mathrm{D} 3$.

\section{SDS-PAGE and Western Blots}

To determine location of Pfs 25 domains during purification and assess purity of refolded domains, we loaded samples from each step of purification onto tris-tricine gels consisting of $4 \%$ stacking gel and $10 \%$ resolving gel and after electrophoresis detected proteins by Western blot. For Western blots we used yeast purified recombinant Pfs 25 from the NIH as a positive control. WE detected His tagged domains using polyclonal anti-Pfs 25 serum diluted 1:250 or monoclonal antibody to 6X-His. For detection of primary antibody we used HRP-conjugates anti-ms IgG at a concentration of 1:1000. 


\section{Statistics}

We assessed statistical significance $(\mathrm{p}<0.05)$ using Student's T Test when comparing two groups. Data is presented as mean +/- SEM. 


\section{CHAPTER THREE}

\section{RESULTS}

\section{EGF domains from Pfs25 are expressed in soluble fraction of BL21 E. coli lysates}

Pfs25 is composed of four EGF-like domains. In its native conformation on the parasite surface, Pfs25 domains 2 and 3 are thought to be the most surface exposed and in a previous study, domain 2 was most highly associated with transmission blocking antibodies (Figure 3, Stowers et al. 2000). To bind to Pfs25 and block transmission, antibodies must be directed at epitopes near sites of interaction with host receptors. Immunizations that direct the antibody response to domains 2 and 3 should be better at blocking transmission than strategies that target portions of Pfs 25 more distal from these host receptor interacting sites or which are not accessible on the parasite surface. To compare domain specific antibody responses to immunization with different Ad vectors, I first had to purify and refold domains 1-4 from Pfs25.

Kumar et al. 2014 reported that Pfs25 expressed in E. coli was present in insoluble cytoplasmic aggregates called inclusion bodies that they isolated by centrifugation after lysis. These aggregates often form during expression of recombinant proteins in E. coli, especially at high levels of expression and are a result of intermolecular interactions of misfolded protein (Palmer and Wingfield 2004). However, expression of smaller fragments of a protein could affect aggregation and reduce inclusion body formation. 
To determine if EGF domain 3 from Pfs 25 is expressed as insoluble aggregates in E. coli, I grew cultures of BL21 E. coli transformed with pET15b-domain 3 to an $\mathrm{OD}_{600}$ of 0.6. After inducing protein expression with IPTG for 4 hours, I pelleted and lysed cells. I loaded supernatant from centrifuged lysate and cell debris in non-denaturing buffer on a tris tricine gel and transferred the band to a nitrocellulose membrane. To detect domain 3, I probed the membrane with an antibody against 6X-His. Unlike Pfs25, domain 3 is soluble, however, based on lack of a distinct band the peptide is most likely forming soluble aggregates (Figure 4). Aggregation is most likely due to intermolecular interactions between misfolded proteins and could be due to disulfide bonds, which would remain intact unless denatured. These aggregates appear to be soluble for domain 3. 


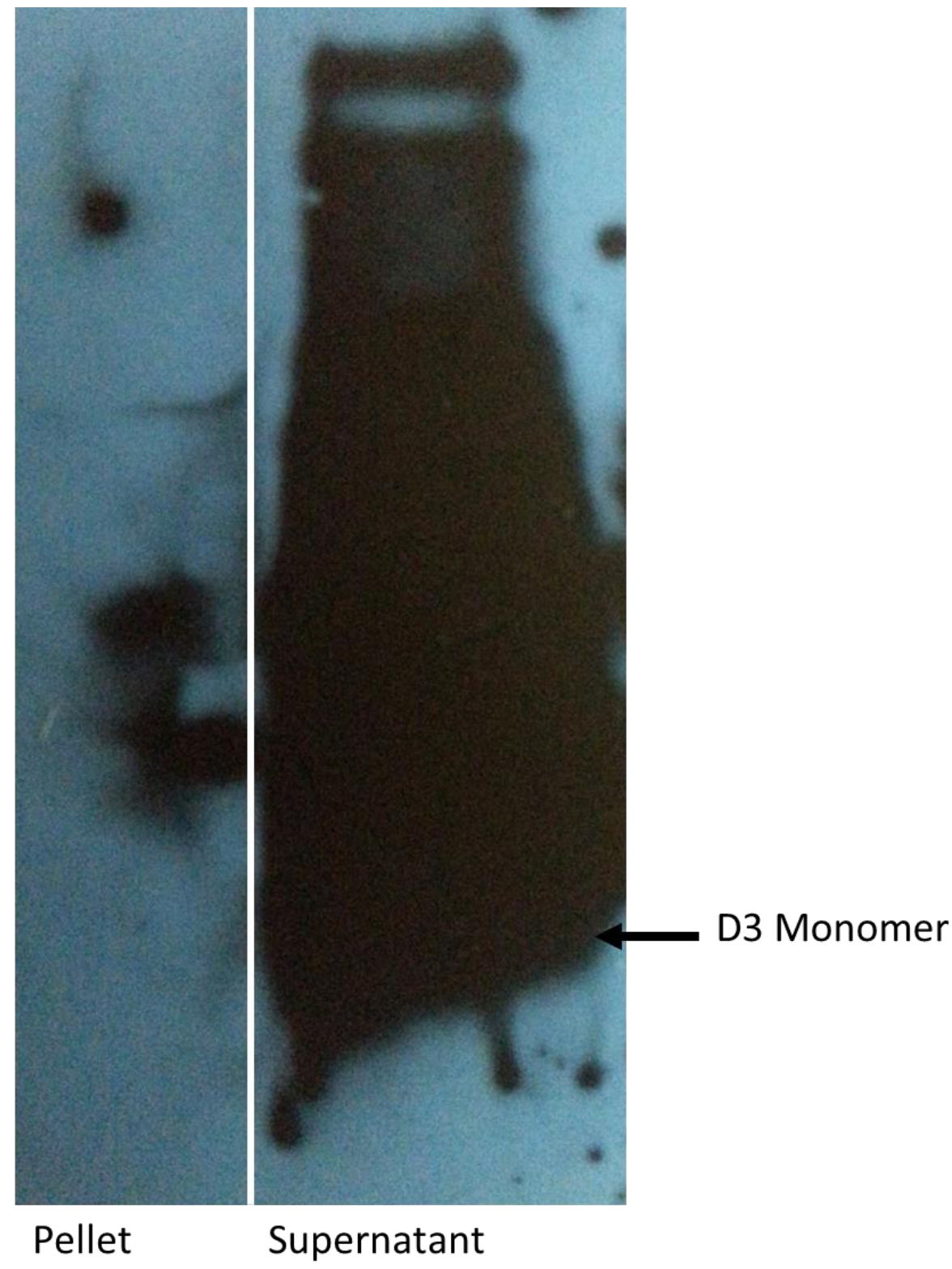

Figure 4: Expression of domain 3 in E. coli. I lysed cells in lysis buffer and pelleted cell debris. I loaded supernatant from lysate and resuspended pellet onto a tris-tricine gel under non-denaturing conditions. After transferring to a nitrocellulose membrane, I detected domain 3 using an antibody against the $6 \mathrm{X}$-His tag present on the peptide. 


\section{Refolding of domains from Pfs25}

Optimal refolding protocols vary even for similar proteins and screening several protocols is usually necessary to identify the most optimal refolding strategy. When refolding proteins that contain disulfide bonds, the first step is denaturing the protein and reducing disulfide bonds, for which I chose urea and $\beta$-ME. Once protein is denatured and reduced, it can be refolded by removing the denaturing reagent, urea, in the presence of a redox system. A mixture of reduced and oxidized glutathione is the most commonly used redox couple. This allows disulfide bonds to reshuffle until they reach the desired conformation. On column refolding allows more time for reshuffling of bonds as the concentration of urea slowly decreases but also leaves the protein more prone to aggregation at intermediate concentrations of urea. Alternatively, rapid dilution in a solution that contains GSH:GSSG but no urea prevents long periods of exposure to aggregation prone conditions but provides less time for refolding. Protein concentration is another important consideration because aggregation occurs more rapidly at high concentrations. The range of $10-100 \mu \mathrm{g} / \mathrm{mL}$ is ideal to preserve the balance between refolding and aggregation (Mamathambika and Bardwell 2008).

I first attempted refolding of domain 3 because I have a conformation specific antibody to an epitope in D3, which I can use to quickly assess folding success using ELISA. I expressed domain 3 in BL21 E. coli and collected lysates. I loaded lysates onto a TALON Cobalt affinity column and refolded domain 3 on the column, or purified it on the column and refolded by dilution. I determined concentration by Bradford assay. Concentrations for several purifications of domain 3 ranged from 74.7-99.4 ng/ $\mu \mathrm{L}$. To 
assess purity of refolded protein, I loaded $0.5 \mu \mathrm{g}$ on a tris tricine gel and used Coomassie dye to detect proteins. Domain 3 peptides from both purification methods did not contain contaminating protein (Figure 5). These results indicate that I successfully isolated domain 3 and that the samples did not contain detectable protein contaminants.

To confirm that the purified protein is domain 3, I coated ELISA plates with equimolar amounts of domain 3 and Pfs 25 that is presumed to be correctly folded (Kaslow et al. 1992) and probed with the conformation independent transmission blocking antibody 4B7. Titers for both purified domains 3 were similar to those for Pfs 25 (Figure 6A). This indicates that the purified peptide is domain 3 and that $4 \mathrm{~B} 7$ titers accurately reflect the expected ratio of coated proteins. To determine if domain 3 is correctly folded, I coated plates with purified domain 3 or Pfs 25 and probed with the conformation dependent transmission-blocking antibody ID2. ELISA titers against either refolded domain 3 preparation were significantly lower than those observed for full length Pfs25 (Figure 6B). This suggests that the ID2 epitope was misfolded in domain 3 compared to full length Pfs25. 


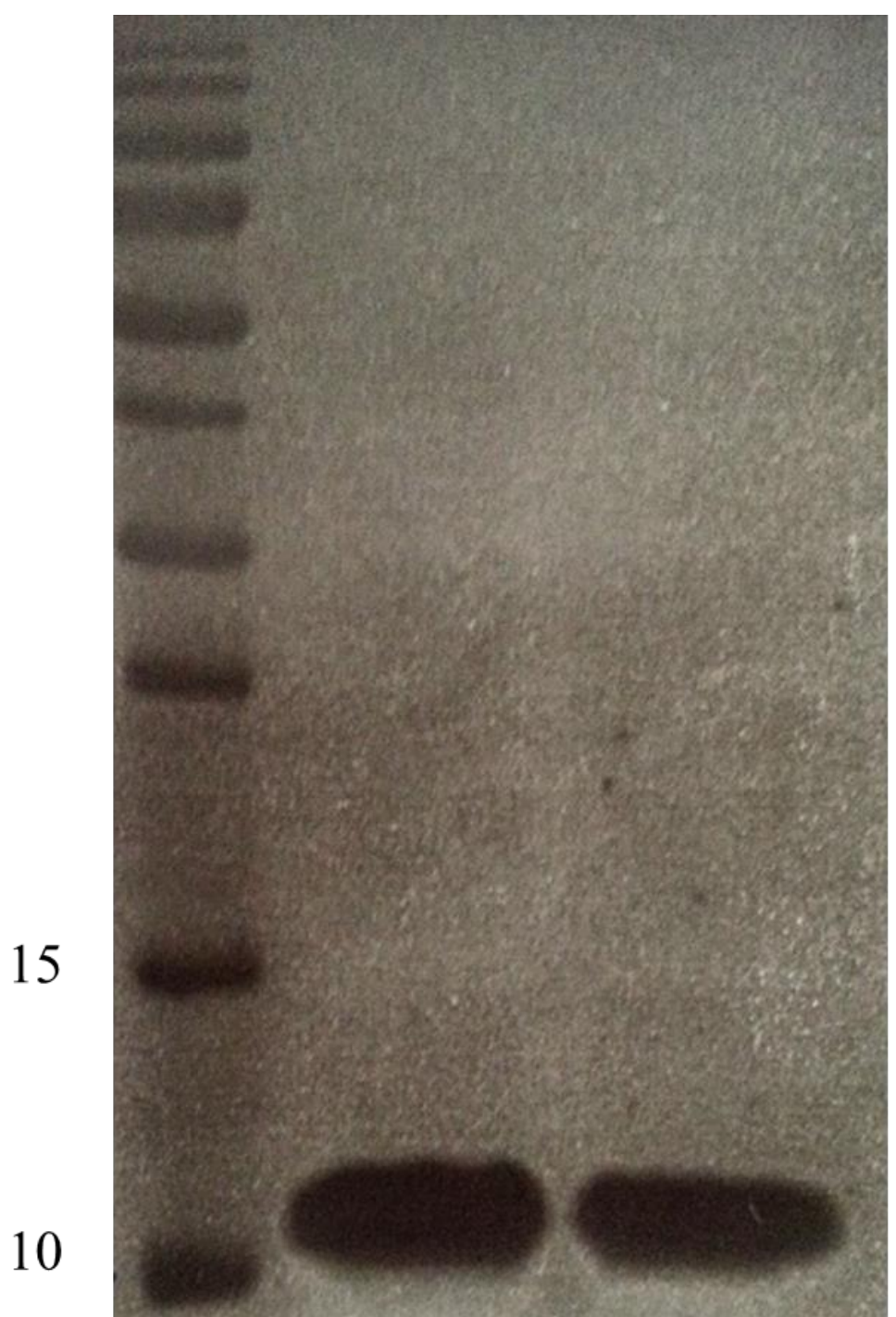

\section{Dilution Column}

Figure 5: Purified and refolded domain 3. I loaded $0.5 \mu \mathrm{g}$ of domain 3 purified and refolded on column and domain 3 purified on column and refolded by dilution onto a tris tricine gel. I loaded samples under reducing conditions. 
Domain Specific ELISA with 4B7

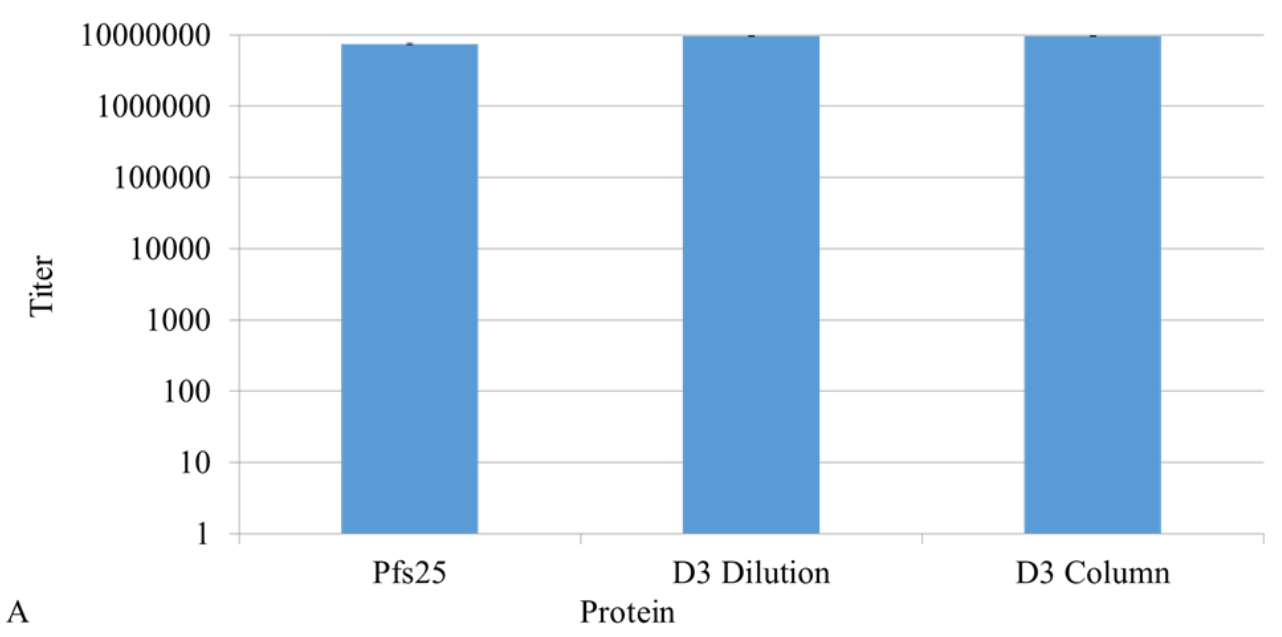

Domain Specific ELISA with ID2

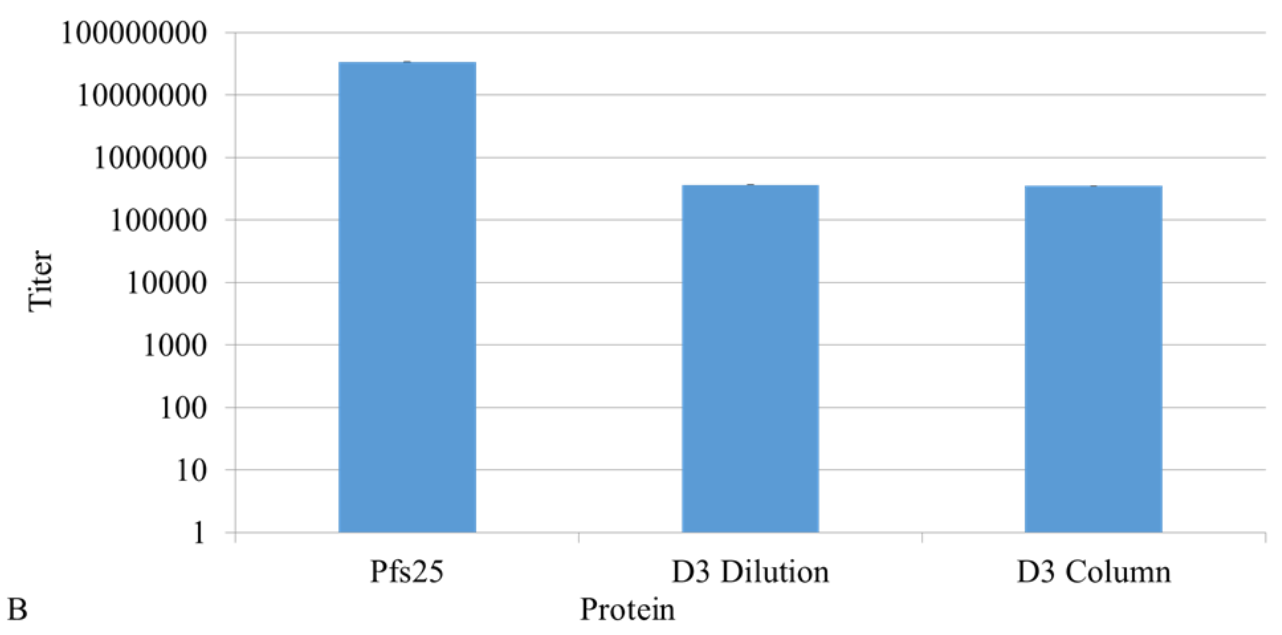

Figure 6: ELISA titers on plates coated with equimolar amounts of Pfs25, D3 refolded on column and D3 refolded by dilution detected using conformation independent monoclonal antibody 4B7 (A) or conformation dependent monoclonal antibody ID2 (B). Titers are shown on an inverse log scale. 


\section{Pfs25 expression by cells infected with Ad5Pfs25exo}

Goodman et al. 2011 immunized mice with Ad vectors encoding a secreted form of Pfs25. Although this approach generated high titers of transmission blocking antibodies, displaying Pfs 25 on the cell surface could more closely mimic its native state and generate a higher quality transmission blocking antibody response focused on surface accessible epitopes. In mice immunized with yeast purified Pfs 25 domains, serum from immunization with domain 2 was most effective at blocking transmission even at low antibody titers (Stowers et al. 2000). Domains 2 and 3 contain predicted B cell epitopes and contain surface loops that are solvent exposed based on modeling. Targeting these two domains could lead to a higher quality transmission blocking response.

Ad5Pfs25exo encodes a form of Pfs25 with no transmembrane domain and is therefore secreted by infected cells. I used IF to confirm that Ad5Pfs25exo infected cells express Pfs25 Figure 7). I treated Ad5Pfs25exo infected $293 \beta 5$ cells with Golgi Stop for four hours to retain Pfs25 in cells and fixed them in 3.7\% PFA. To visualize Pfs25, I probed with a monoclonal antibody against Pfs25. Infected cells stained positive for intracellular Pfs25. This indicates that cells infected with Ad5Pfs25exo express the transgene. 


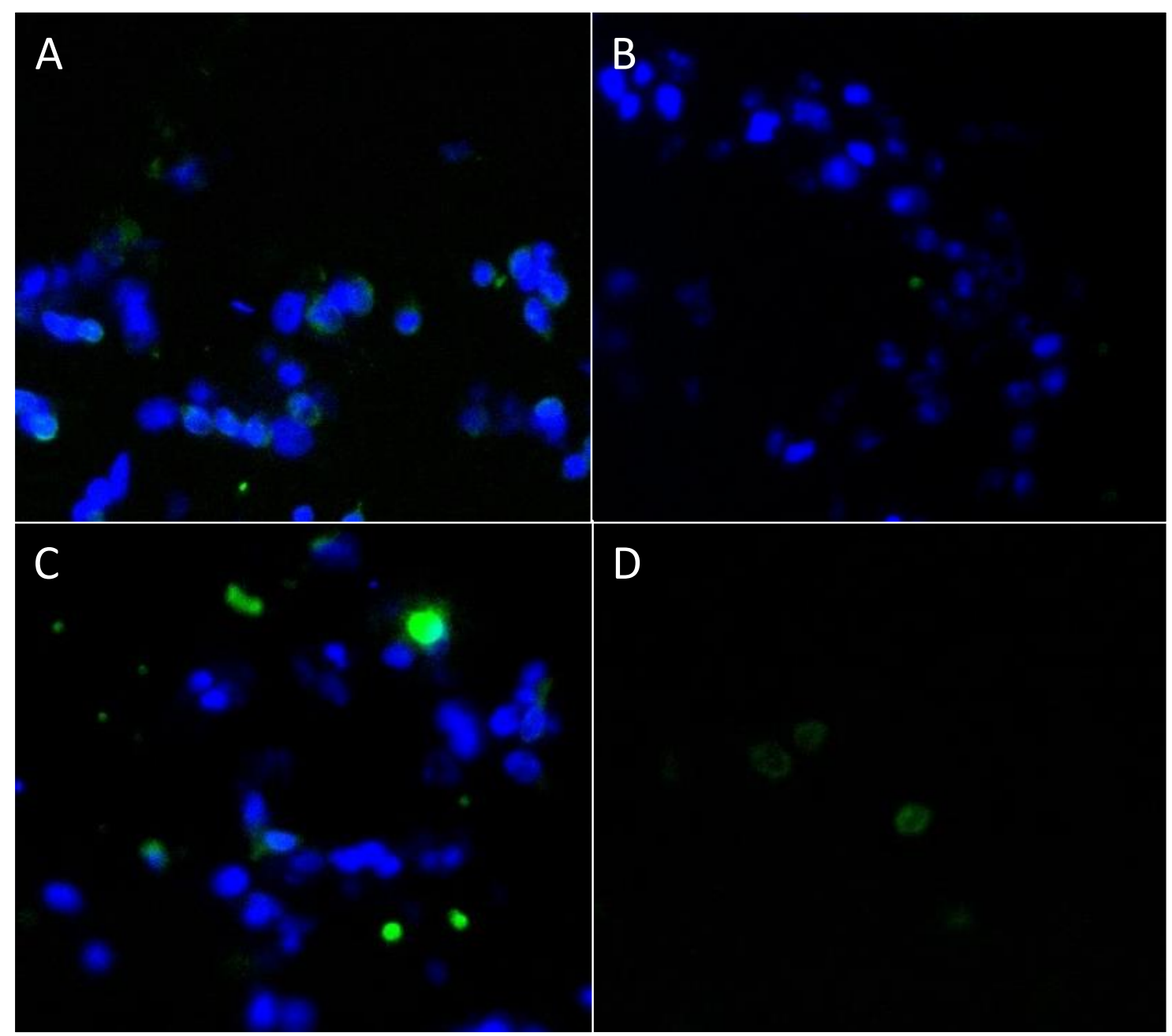

Figure 7: IFA of $293 \beta 5$ cells infected with Ad5Pfs25exo. I infected $293 \beta$ cells with Ad5Pfs25exo overnight. To prevent secretion of Pfs25, I treated cells with GolgiStop for four hours before I fixed infected cells in $3.7 \%$ PFA and stained them with a monoclonal antibody against Pfs25 (4B7). (A) cells infected with Ad5Pfs25 as a positive control. (B) uninfected cells. Two different images of cells infected with Ad5Pfs25exo shown with DAPI staining (C) and without DAPI staining (D). 
Immunization with Ad5Pfs25exo generates lower antibody titers compared to immunization with Ad5Pfs25

To determine if membrane bound Pfs 25 elicits similar antibody titers to whole Pfs25 as soluble Pfs25, I immunized mice with Pfs25-alum, Ad5Pfs25 and Ad5Pfs25exo and collected serum after 21 days. Ad5Pfs25exo expresses a Pfs25 transgene with transmembrane domain removed. Mice immunized with Ad5Pfs25exo develop lower antibody titers than mice immunized with Ad5Pfs25, which indicates that membrane bound Pfs 25 is a superior immunogen to soluble Pfs25 (Figure 8). Pfs25alum generates the lowest antibody titers. These results support using Ad5Pfs25 for primary immunization. 


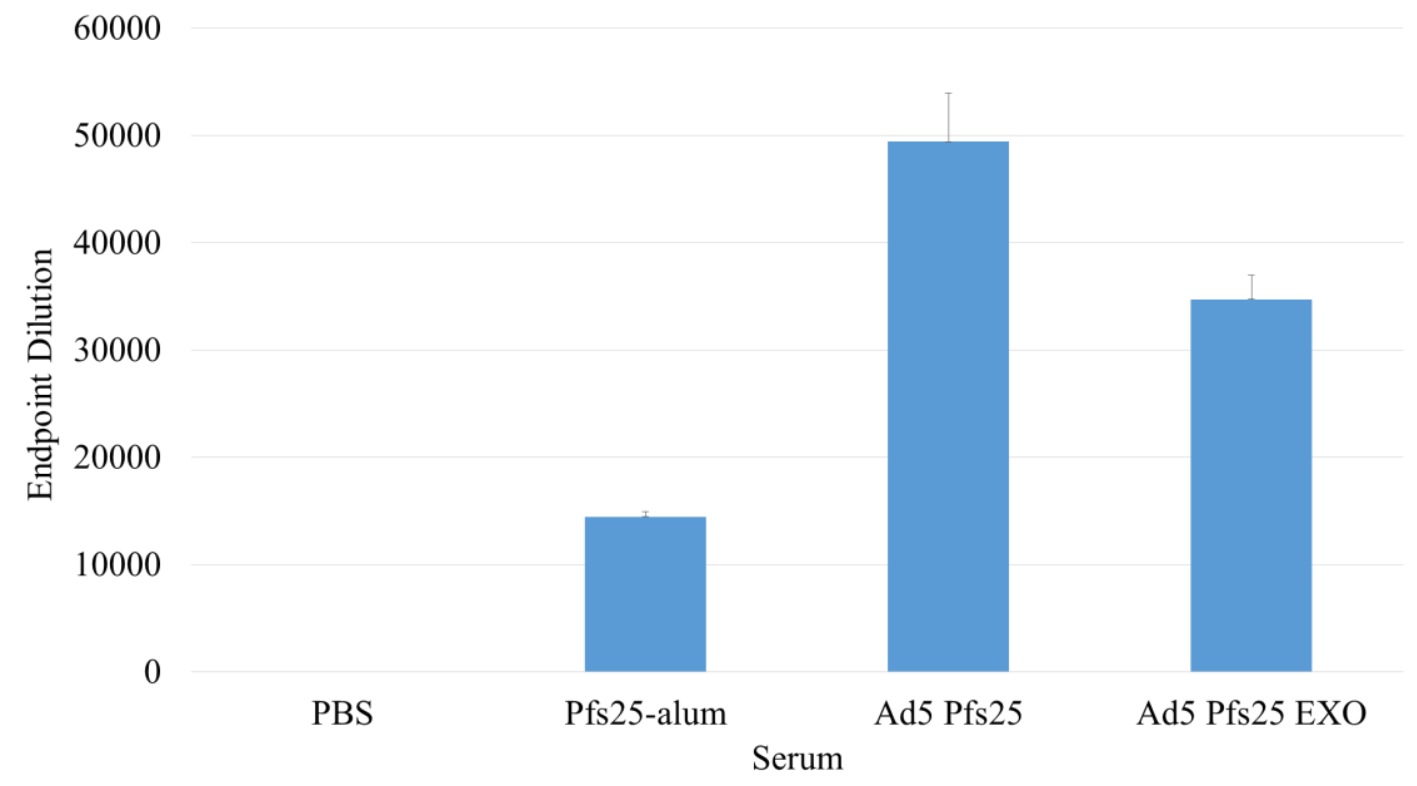

Figure 8: Antibody titers by ELISA in serum from mice immunized with Pfs25-alum, Ad5Pfs 25 and Ad5Pfs25exo. I immunized mice with $2.5 \mu \mathrm{g}$ protein or $10^{9}$ viral particles and collected serum after 21 days. 


\section{Immunization with Ad5Pfs25exo targets different EGF like domains than Ad5Pfs25}

Mice immunized with soluble recombinant Pfs25 develop similar antibody titers to each domain (Stowers et al. 2000). I expected that membrane bound Pfs 25 would alter the balance of antibody response to domains that are more surface accessible and therefore more likely to be important for transmission blocking. In contrast, I expected soluble Pfs 25 delivered as Ad5Pfs25exo would activate more cells reactive against domains that are not normally accessible on the parasite surface. In particular domain 2 has been associated with the highest level of transmission blocking and domains 2 and 3 contain the most likely predicted B cell epitopes (Stowers et al. 2000). A TBV that preferentially targets these domains would be more effective than a vaccine that targets epitopes that are not surface accessible. I purified and refolded domains 1-4 according to the on column purification and refolding by dilution protocol used for domain 3 .

To assess which Pfs25 domains are targeted by immunization with Ad5Pfs25 or Ad5Pfs25exo, I coated plates with domains 1-4 and probed with serum from immunized mice. Ad5Pfs25 and Ad5Pfs25exo elicit equivalent titers of antibodies against domain 3, which contains the best predicted B cell epitopes. Additionally, Ad5Pfs25 serum contains high titers to domain 1 (Figure 9). 


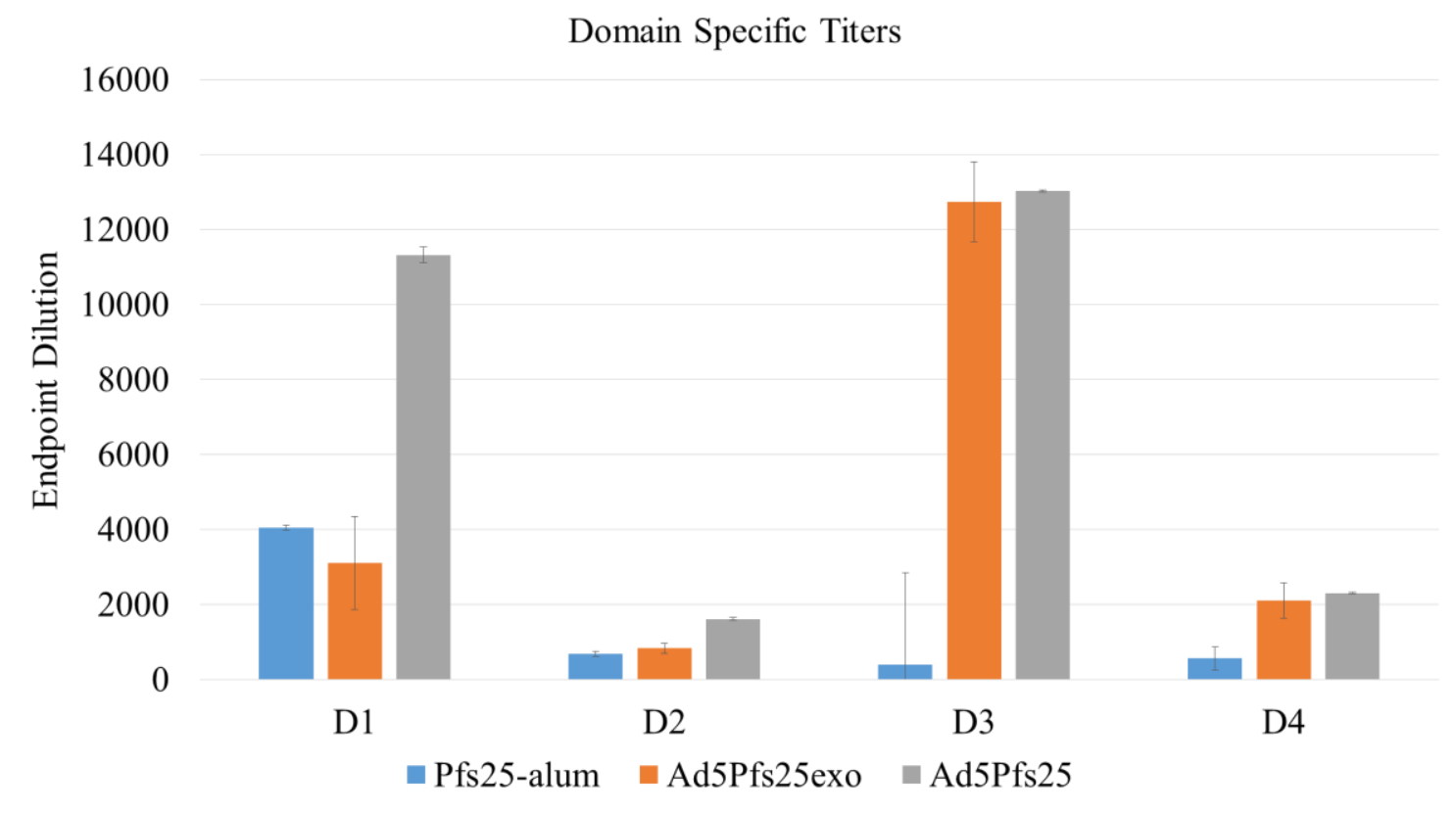

Figure 9: Domain specific antibody titers by ELISA using serum from mice immunized with Ad5Pfs 25 or Ad5Pfs25exo. I immunized mice with $10^{9}$ viral particles and collected serum after 21 days. For ELISA, I coated plates with 25ng of Pfs 25 domains and probed with serum from immunized mice. 


\section{Domain specific antibody response to AdCD vectors}

Mice immunized with individual yeast purified domains followed by boost with full length Pfs25 develop similar titers to all 4 domains despite low domain specific titers after primary immunization with domains 3 and 4 (Stowers et al. 2000). This indicates that antigen primed cells to each domain can be boosted even if prime immunization generates a weak domain specific antibody response. To generate the most effective TBV, we need to target Pfs25 epitopes that are surface exposed and can elicit the strongest B cell response.

I expected immunizing mice with vectors that display epitopes from Pfs 25 to focus the antibody response to the domain where the epitope is found. This would generate a higher quality transmission blocking response by targeting biologically relevant portions of Pfs25. I used serum from mice immunized with Pfs25-alum and boost immunized with Pfs25-alum, Ad5HVR5D2 or Ad5HVR5D3 for ELISA on plates coated with domains 1-4. I used Pfs25-alum for primary immunization instead of Ad5Pfs25 to avoid generating neutralizing antibodies to the vector, which could reduce the efficacy of $\mathrm{Ad}_{\mathrm{CD}}$ vectors. Ad5HVR5D3 increases antibody titers to domain 3 relative to both Ad5HVR5D2 and Ad5Pfs25-alum, suggesting that this may be a means to better focus antibody responses to transmission blocking epitopes (Figure 10). Unexpectedly, Ad5HVR5D2 did not increase titers to domain 2 relative to the other sera tested. 


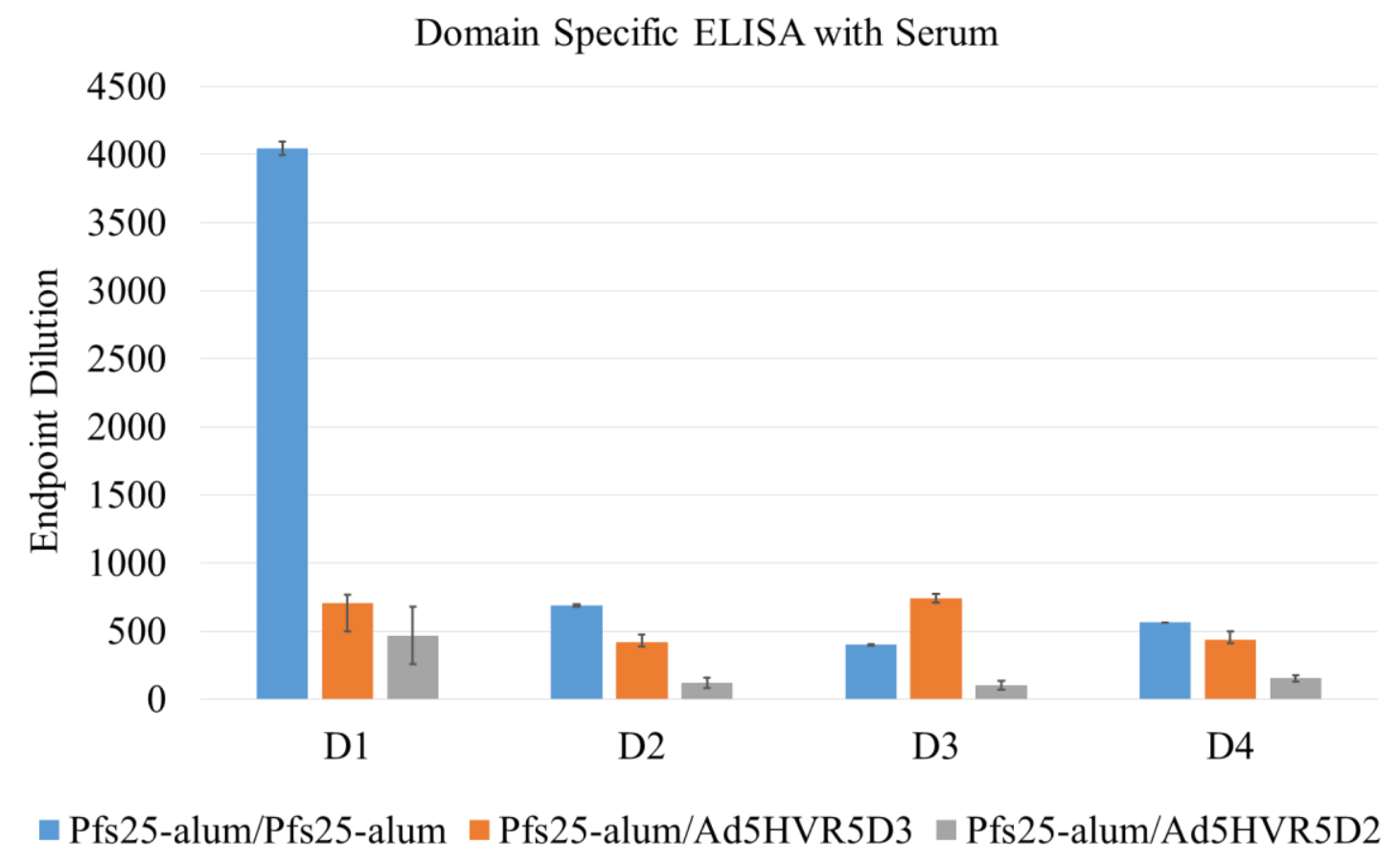

Figure 10: Domain specific ELISA titers for serum from mice primed with Pfs25-alum and boost immunized with Pfs25-alum, Ad5HVR5D2 or Ad5HVR5D3. Protein immunization was with $2.5 \mu \mathrm{g}$ Pfs 25 and virus immunizations were with $10^{10}$ viral particles. 


\section{Transmission blocking activity of serum from mice immunized with AdCD}

I expected immunization with $\mathrm{Ad}_{\mathrm{CD}}$ to focus the antibody response against $\mathrm{Pfs} 25$ to epitopes that are surface exposed and highly correlated with transmission blocking activity. Although Ad5Pfs25/Ad $\mathrm{CD}$ immunized mice develop lower antibody titers than mice boost immunized with Pfs 25 -alum, the antibody response should be more focused to capsid displayed epitopes. If these epitopes are the target of transmission blocking antibodies, then I expect to see a potent transmission blocking response even with lower antibody titers.

I assessed transmission blocking activity using SMFA, where mosquitoes feed on serum from immunized mice mixed with P. falciparum gametocytes. SMFA was performed by K. Miura and C. Long at the NIH. At the highest dilution used (1:20), serum from mice immunized with Ad5Pfs25 and boost immunized with Pfs25-alum or Ad $_{\mathrm{CD}}$ blocked formation of oocysts (Figure 11). Serum from mice immunized with Pfs25-alum/Pfs25-alum did not inhibit parasite transmission more than serum from mice immunized with empty Ad5 vector. 


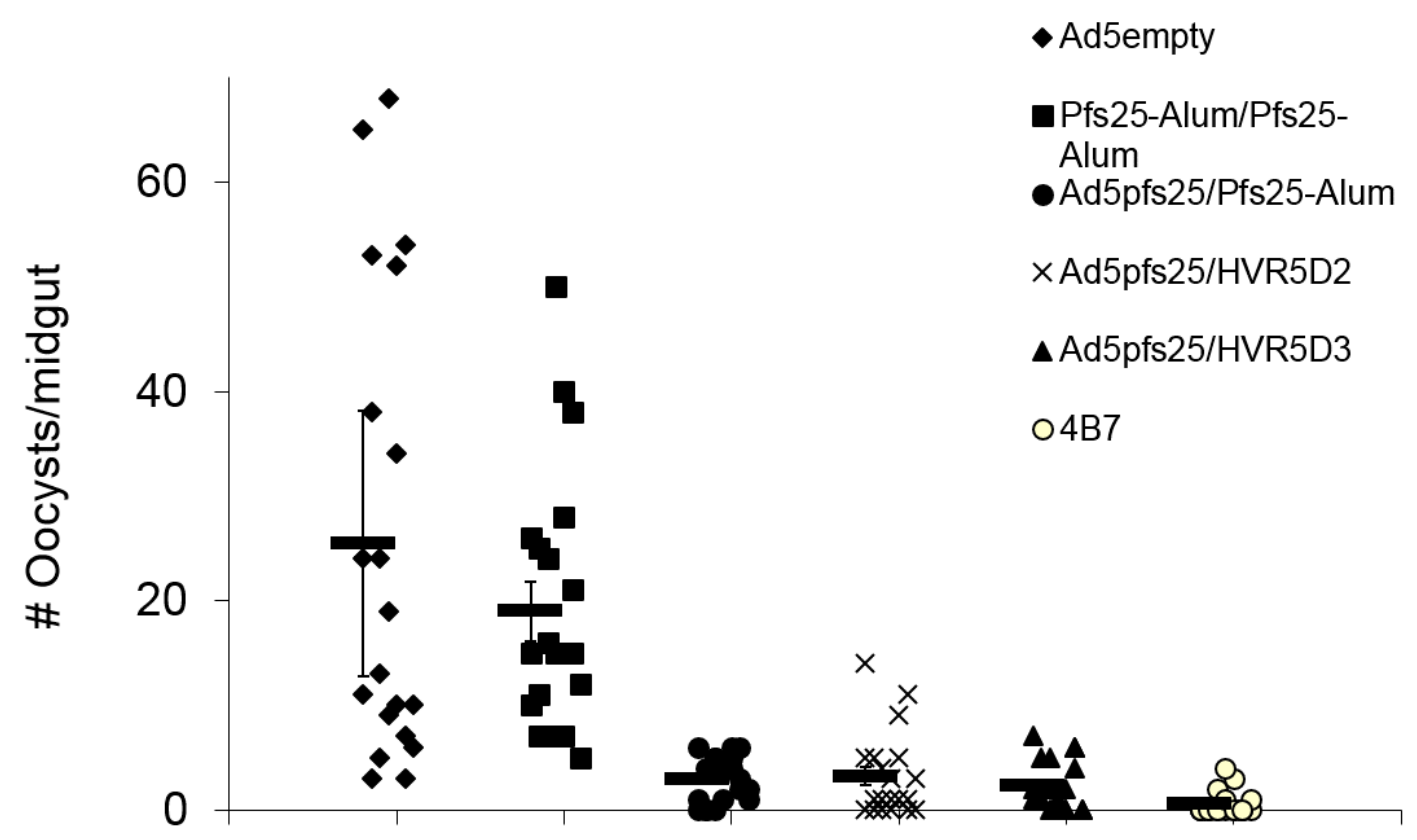

Figure 11: Transmission blocking activity of serum from mice immunized with Ad5Pfs25/Ad ${ }_{\mathrm{CD}}$ compared to Ad5Pfs25/Pfs25-alum and Pfs25-alum/Pfs25-alum measured by standard membrane feeding assay. Serum was diluted 1:20. 4B7 is a monoclonal antibody against an epitope in Pfs25 used as a control. 


\section{A new epitope from Pfs25 domain 3}

So far I have created vectors that display two epitopes, D2 and D3. However, these only represent two surface exposed loops on Pfs 25 and are not the only potential epitopes in domains 2 and 3 (Figure 3). Eventually, I could use a combination of $\mathrm{Ad}_{\mathrm{CD}}$ displaying different epitopes for boost immunization to focus the antibody response to epitopes associated with transmission blocking.

I used ElliPro B cell epitope prediction software to identify a new epitope to use in $\mathrm{Ad}_{\mathrm{CD}}$ vectors, D3C. D3C is an epitope in domain 3 that is the second most likely predicted B cell epitope in Pfs25 after D3 and is found on the second loop in Pfs 25 domain 3 (Figure 3). Ad5HVR5D3C PF has similar viral titers to other $\mathrm{Ad}_{\mathrm{CD}}$, which indicates that it is able to effectively replicate. Antibody titers by ELISA to serum from mice immunized with Ad5Pfs25 and boost immunized with Ad5HVR5D3C PF are comparable to mice immunized with Ad5HVR5D3 with or without PF and lower than for mice immunized with Ad5HVR5D2 (Figure 12). 


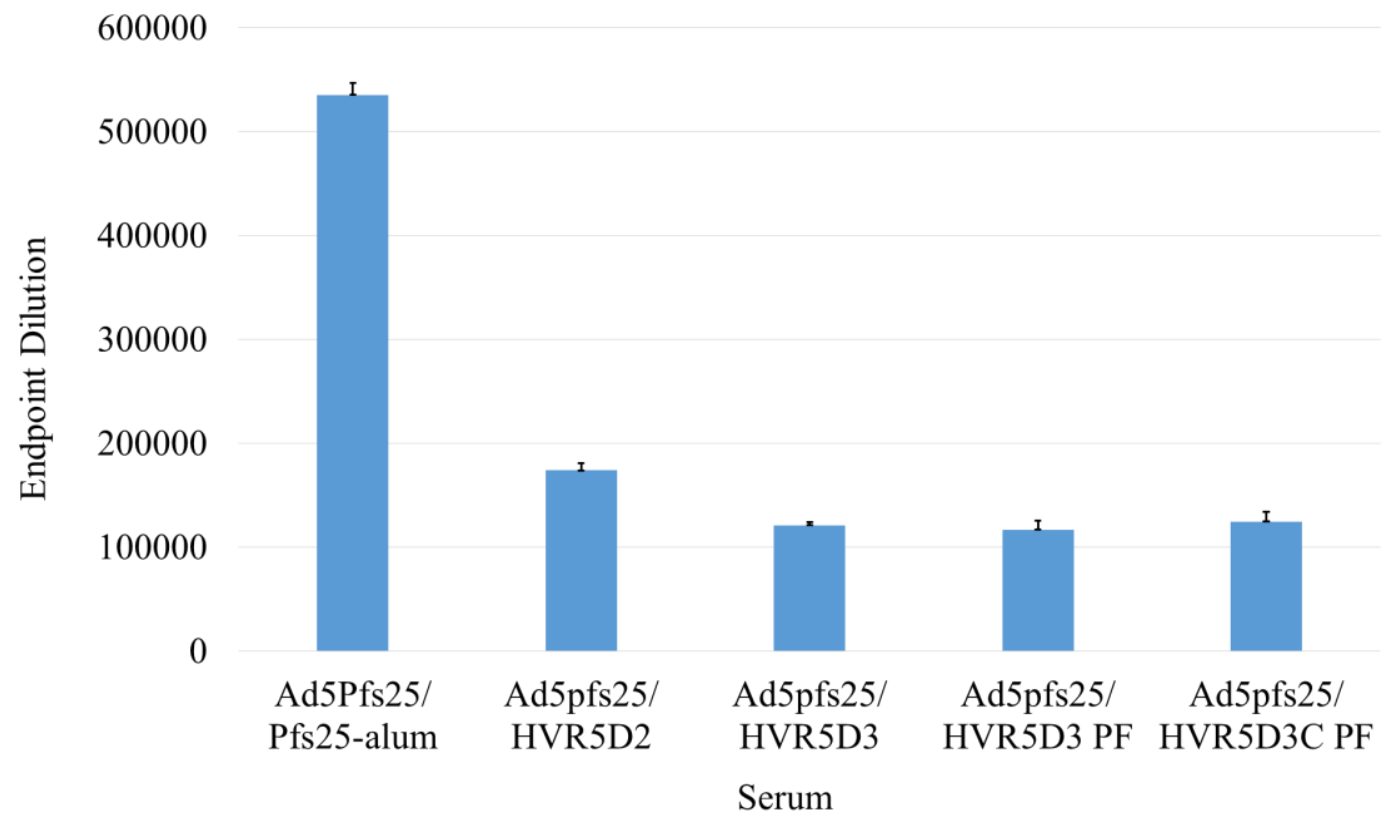

Figure 12: Comparison of antibody titers by ELISA for serum from mice immunized with Ad5Pfs25/Pfs25alum and four $A_{C D}$ vectors. 


\section{AdCD vectors with FliC do not induce higher antibody titers than AdcD vectors without FliC}

Flagellin (FliC) has previously been used as an adjuvant to increase antibody titers and is a potent activator of multiple innate and adaptive immune pathways (Mizel and Bates 2010). I have developed Ad vectors with a C-terminal peptide from FliC appended to pIX and capsid displayed Pfs25 epitopes. I expected that vectors with FliC would elicit higher antibody titers than vectors without FliC. I previously made $\mathrm{Ad}_{\mathrm{CD}}$ displaying the D3 epitope in HVR5 and compared them to Ad5HVR5D3 PF.

I boost immunized Ad5Pfs25 primed mice with Ad5HVR5D3 with or without FliC attached to pIX. I collected serum after 21 days and used it to probe ELISA plates coated with Pfs25. I did not detect a significant difference between serum from mice immunized with $\mathrm{Ad}_{\mathrm{CD}}$ or $\mathrm{Ad}_{\mathrm{CD}} \mathrm{PF}$ (Figure 13). This indicates that capsid displayed FliC does not improve the antibody response to D3 displayed in HVR5. To determine if boost immunization with $\mathrm{Ad}_{\mathrm{CD}} \mathrm{PF}$ affects titers to Ad5 capsid, I coated ELISA plates with Ad5 capsid and probed with serum from immunized mice. Mice immunized with vectors that contain PF develop higher antibody titers compared to vectors with wild type pIX (Figure 14). 
pIX FliC ELISA Titers to Pfs25

130000

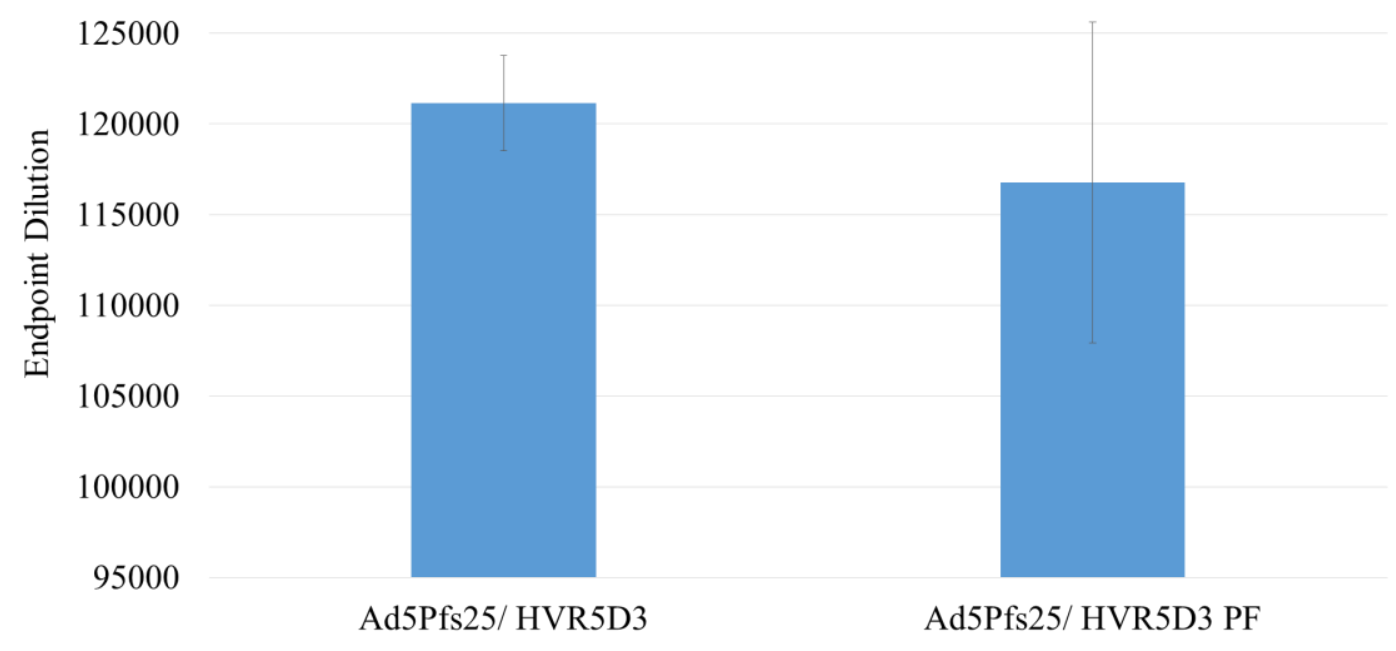

Figure 13: Antibody titers by ELISA for serum from mice immunized with $10^{9}$ viral particles Ad5Pfs 25 and boost immunized with $10^{10}$ viral particles Ad5HVR5D3 or Ad5HVR5D3 PF. I collected serum 21 days after boost immunization. 


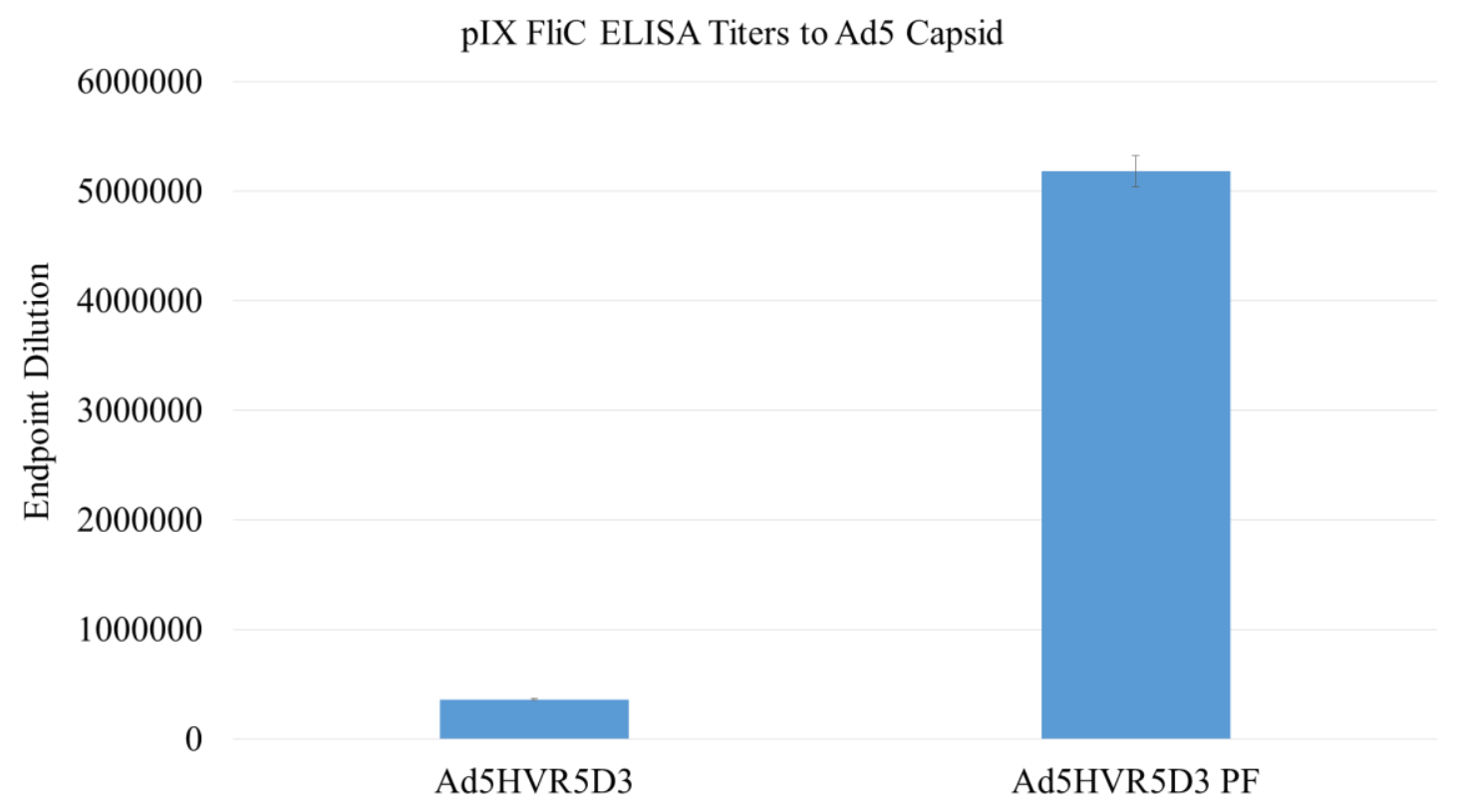

Figure 14: Antibody titers to Ad5 capsid for mice immunized with $10^{9}$ viral particles Ad5Pfs 25 and boost immunized with $10^{10}$ viral particles Ad5HVR5D3 or Ad5HVR5D3 PF. I collected serum 21 days after boost immunization. 


\section{CHAPTER FOUR}

\section{DISCUSSION}

Despite decreasing incidence and mortality, malaria due to Plasmodium falciparum continues to be a problem and eradication requires ongoing efforts. As drug resistance spreads and mosquitoes become resistant to insecticides, the need for new drugs and vaccines becomes more urgent to achieve the current goal of complete eradication. Several vaccine candidates have been identified to target multiple stages in the lifecycle of P. falciparum, including transmission blocking vaccines that target the sexual stages. Of the sexual stage antigens, Pfs 25 has been studied the most and has been

used in clinical trials with various adjuvants. Antibodies to Pfs25 have also been found to be more effective at blocking transmission than antibodies to any other P. falciparum protein. I have developed Ad vectors to deliver Pfs 25 or selected epitopes from Pfs 25 and propose Ad vectors as the best adjuvant for creating an effective TBV against Pfs25.

My goal in this work was two-fold. First, I wanted to determine whether I could better focus antibody responses to transmission blocking antigens so that transmission blocking antibody titers would be higher. Second, I wanted to determine whether enhancing the immunogenicity of adenovirus vaccine vectors could further increase transmission blocking antibody titers to Pfs 25 .

\section{Refolding of Pfs25 D3}


Using ID2, I did not detect significantly elevated titers to domain 3 by ELISA. This indicates that the epitope for ID2 is not folded correctly but other portions of the domain could be folded correctly. In previous work, ID2 was used to monitor success in refolding whole Pfs25 before proceeding to more accurate methods (Kumar et al. 2014). In addition to assessment using ID2, I could use circular dichroism spectropolarimetry to assess secondary structure and eventually I would use NMR to assess the complete structure, which would provide more information than only assessing one epitope.

Protein refolding is a complicated process and ideal conditions vary even for similar proteins. This is particularly true for cysteine rich proteins with disulfide bonds that are essential to their structure, such as EGF proteins. Despite many successful purifications of recombinant proteins from E. coli, we are unable to accurately predict the best refolding protocol for a given protein and refolding attempts usually involve trials with many different protocols and reagents. The refolding conditions that worked for whole Pfs25 may not be effective for refolding individual domains. Future attempts to refold D3 should use varying concentrations of denaturing agent because overly aggressive denaturation of peptide could reduce the success of refolding. Additionally, I could vary the time protein is allowed to refold to allow more time for shuffling of disulfide bonds until they assume the proper arrangement. If I removed urea too rapidly at a stage where disulfide bonds were beginning to correctly form then I might have missed a critical point in refolding. I could also try different redox couples or change the GSH:GSSG ratio, which is important because these reagents stabilize intermediate forms of cysteine during formation of disulfide bonds. 


\section{Domain specific ELISA}

I only assessed the refolding of domain 3 but I purified all four domains using the most efficient protocol I tried. Although I used these domains for ELISA, I do not know how efficiently my protocol refolded them. ID2 is one of two purified monoclonal antibodies to Pfs 25 available and is the only conformation dependent one. Due to the variability in refolding conditions for different proteins, any of the other domains could have been refolded more or less efficiently than the others using the same protocol. I could assess the refolding of the other domains using NMR. However, even with this variability, domain specific titers to partially correct peptides can provide information about the differences between immunizations.

Despite uncertainty in the proper folding of the individual Pfs25 EGF domains, antibodies to Pfs 25 and Pfs25exo bind domain 3 equally. These similar titers to D3 are not surprising because D3 contains the two most likely predicted B cell epitopes in Pfs 25. The major difference in domain specificities between antisera from Ad5Pfs25 and Ad5Pfs25exo immunized mice were in binding to domain 1. I did not assess transmission blocking activity of Ad5Pfs25exo serum and therefore I cannot say whether increased titers to domain 1 in mice immunized with Ad5Pfs25 are related to transmission blocking. According to Stowers et al. 2000, high titers of antibodies to domain 1 correlate with transmission blocking activity but only domain 2 immunized serum blocked transmission at low antibody titers. Based on this, the higher response to domain 1 could be relevant for transmission blocking. 
When I assessed the targeting of domain 2 or domain 3 using capsid displayed epitopes from each domain, I found that Ad5HVR5D3 increased antibody titers to domain 3 but Ad5HVR5D2 did not increase antibody titers to domain 2 and the overall titers for each domain were lower for Ad5HVR5D2. This is unexpected because ELISA using plates coated with correctly folded Pfs25 shows that Ad5HVR5D2 elicits similar antibody titers to the whole protein as Ad5HVR5D3. This could be indicative of the limitations of my most likely misfolded proteins, which might not be recognized by serum antibodies. Alternatively, if the D2 epitope is not displayed in a native conformation in hexon, this could affect the effectiveness of targeting the antibody response to that epitope in the context of native protein. Based on B cell epitope prediction, the D2 epitope is the most likely surface accessible B cell epitope in Pfs 25 but this could be incorrect. Immunization with Ad5HVR5D3 increases antibody titers to domain 3 relative to Pfs 25 -alum immunization, which suggests that this vector successfully shifts the antibody response to the D3 epitope. If domain 3 was correctly folded, I expect that titers would be even higher.

\section{Creating new AdcD vectors}

Although I successfully purified a vector displaying a new epitope from domain 3, Ad5HVR5D3C, I also unsuccessfully tried to propagate a virus displaying another epitope from domain 2, Ad5HVR5D2B, and a virus displaying a modified version of the D3 epitope, Ad5HVR5D3B, based on B cell epitope prediction. This shows the limitations of displaying certain sequences on the capsid surface. The unsuccessful viruses could not be efficiently propagated, which suggests that the inserted sequences 
interfere with proper capsid assembly. The best solution to this problem would be to identify predictors of success when inserting epitopes into the capsid and this would be a major advancement in our knowledge of manipulating Ad vectors. If I could identify parameters that predict success for insertion into hexon, then I could more effectively design epitopes for $\mathrm{Ad}_{\mathrm{CD}}$ that do not interfere with virus propagation.

I designed new $\mathrm{Ad}_{\mathrm{CD}}$ using SwissProt modeling software to measure the distance between the first and last residues of the Pfs25 loop to replace a loop of similar width in HVR5. Additionally, I lined up cysteines that form disulfide bonds. I expected that preserving disulfide bonds would add support to the structure and help with correct display. Only one vector out of three grew, which suggests that predicting size by modeling is not sufficient to predict success. Leaving disulfide bonds also did not improve success at generating virus. This could be due to unfavorable constraints imposed by having a disulfide bond that might interfere with capsid assembly in some Ad $_{\mathrm{CD}}$. In this case the $\mathrm{D} 3 \mathrm{C}$ loop might allow a conformation that is more favorable for capsid assembly compared to D3B and D2B. This could be resolved by omitting the cysteines in those loops, which could increase flexibility at the point of contact with HVR5.

\section{Focusing the antibody response to transmission blocking epitopes}

Domain specific ELISA did not support the ability of Ad5HVR5D2 to target transmission blocking epitopes but SMFA data and anti-Pfs25 ELISA data suggest that this vector, as well as Ad5HVR5D3 improves the quality of the transmission blocking response. Although $\mathrm{Ad}_{\mathrm{CD}}$ boost immunization generates several-fold lower ELISA titers 
than boost immunization with Pfs25-alum, serum from mice immunized with Ad5Pfs25/Ad5 $\mathrm{CD}$ blocks P. falciparum transmission as well as serum from mice immunized with Ad5Pfs25/Pfs25-alum. This indicates that $\mathrm{Ad}_{\mathrm{CD}}$ generate a more potent, but less abundant transmission blocking antibody response. For a more accurate comparison of the most effective immunizations, I would need to dilute serum used for SMFA until transmission is no longer blocked, since at a 1:20 dilution, all sera completely blocked transmission.

Future experiments should test the efficacy of immunizing with a combination of Ad $_{\mathrm{CD}}$ to target several surface exposed epitopes. I expect that using multiple $\mathrm{Ad}_{\mathrm{CD}}$ would improve the transmission blocking activity of serum from immunized mice by focusing the response to multiple epitopes. This approach would also reduce the likelihood of vaccine resistant strains developing by not putting selective pressure on a single epitope. Additionally, I would assess whether using certain epitopes produces more long lived plasma cells. This is an important predictor of vaccine success because a TBV targeting Pfs25 cannot be successful without persistent antibody secretion long after immunization. Heterologous prime boost immunization with different Ad serotypes could improve the antibody response by reducing competition between activation of Pfs 25 and capsid reactive memory cells.

\section{Effect of capsid displayed FliC on antibody response to AdcD vectors}

FliC has been used as an adjuvant to increase antibody titers to antigen. In previous studies, researchers have administered FliC fused to antigen and as a mixture of antigen and FliC (Girard et al. 2011, Taylor et al. 2011). Both strategies result in higher 
antibody titers, increased activation of a $\mathrm{T}_{\mathrm{H}} 2$ helper $\mathrm{T}$ cell response and increased retention of antigen in draining lymph nodes. I expected that by attaching a domain of FliC to Ad5 capsid to selectively activate the inflammasome and not TLR5, I would also increase antibody titers to capsid displayed antigen. However, I did not see a difference in antibody response to the Pfs25 epitope displayed on the capsid (Figure 13). I did, however, observe a tremendous increase in the antibody response to the rest of the Ad5 capsid (Figure 14).

Since Ad proteins outnumber the single Pfs 25 epitopes, I expect that after priming immunization has generated a response to capsid and Pfs25, boost immunization with an Ad vector of the same serotype would expand mostly cells reactive against capsid. This could deplete extra resources and reduce the expansion of memory B cells reactive to the Pfs25 epitope. In this case the effect of FliC is evident when I look at anti capsid titers. I could overcome this by using a different serotype Ad that would not contain many overlapping epitopes with Ad5. Priming with this vector and boosting with $\mathrm{Ad} 5 \mathrm{CD}$ might favor expansion of B cells reactive to capsid displayed Pfs25 epitopes over anti-capsid cells.

\section{Concluding remarks}

Although I was unable to purify and refold EGF like domains from Pfs25, I tested protocols that could be modified in the future to properly refold the peptides by changing the reaction conditions. Using these peptides I saw some differences in domain specific responses to Pfs 25 but could only draw limited conclusions for this, especially using Ad5Pfs25exo. Ad5HVR5D3 appears to focus the antibody response to domain 3 using 
my assay, unlike Ad5HVR5D2 and domain 2. Although our PF vectors did not enhance the antibody response to Pfs25, this does not mean that FliC is not effective in conjunction with Ad vectors and I would investigate other methods of delivering FliC with Ad vectors. SMFA data provides the strongest support for using $\operatorname{Ad}_{\mathrm{CD}}$ vectors to focus the antibody response to certain Pfs25 epitopes and new epitopes should be identified that are compatible with insertion into hexon.

An effective TBV for P. falciparum would improve our ability to eradicate malaria and would be useful in conjunction with vaccines that target other lifecycle stages but are not $100 \%$ effective, such as RTS,S. This combination would protect individuals but in cases where gametocytes develop the TBV component would provide a major public health benefit by breaking the transmission cycle. 


\section{REFERENCES}

Ahman, H., Käyhty, H., Vuorela, A., Leroy, O., and Eskola, J. (1999). Dose dependency of antibody response in infants and children to pneumococcal polysaccharides conjugated to tetanus toxoid. Vaccine 17, 2726-2732.

Akira, S., and Hemmi, H. (2003). Recognition of pathogen-associated molecular patterns by TLR family. Immunology Letters 85, 85-95.

Alonso, P.L., Brown, G., Arevalo-Herrera, M., Binka, F., Chitnis, C., Collins, F., Doumbo, O.K., Greenwood, B., Hall, B.F., Levine, M.M., et al. (2011). A Research Agenda to Underpin Malaria Eradication. PLoS Medicine 8, e1000406.

Anders, R.F. (1986). Multiple cross-reactivities amongst antigens of Plasmodium falciparum impair the development of protective immunity against malaria. Parasite Immunol. 8, $529-539$.

Anderson, R.D., Haskell, R.E., Xia, H., Roessler, B.J., and Davidson, B.L. (2000). A simple method for the rapid generation of recombinant adenovirus vectors. Gene Ther. 7, 10341038.

Appledorn, D.M., Patial, S., McBride, A., Godbehere, S., Van Rooijen, N., Parameswaran, N., and Amalfitano, A. (2008a). Adenovirus vector-induced innate inflammatory mediators, MAPK signaling, as well as adaptive immune responses are dependent upon both TLR2 and TLR9 in vivo. J. Immunol. 181, 2134-2144.

Appledorn, D.M., McBride, A., Seregin, S., Scott, J.M., Schuldt, N., Kiang, A., Godbehere, S., and Amalfitano, A. (2008b). Complex interactions with several arms of the complement system dictate innate and humoral immunity to adenoviral vectors. Gene Ther. 15, 16061617.

Arakawa, T., Komesu, A., Otsuki, H., Sattabongkot, J., Udomsangpetch, R., Matsumoto, Y., Tsuji, N., Wu, Y., Torii, M., and Tsuboi, T. (2005). Nasal Immunization with a Malaria Transmission-Blocking Vaccine Candidate, Pfs25, Induces Complete Protective Immunity in Mice against Field Isolates of Plasmodium falciparum. Infection and Immunity 73, 7375-7380.

Audran, R., Cachat, M., Lurati, F., Soe, S., Leroy, O., Corradin, G., Druilhe, P., and Spertini, F. (2005). Phase I malaria vaccine trial with a long synthetic peptide derived from the merozoite surface protein 3 antigen. Infect. Immun. 73, 8017-8026. 
Barlan, A.U., Danthi, P., and Wiethoff, C.M. (2011). Lysosomal localization and mechanism of membrane penetration influence nonenveloped virus activation of the NLRP3 inflammasome. Virology 412, 306-314.

Barouch, D.H., Kik, S.V., Weverling, G.J., Dilan, R., King, S.L., Maxfield, L.F., Clark, S., Ng'ang'a, D., Brandariz, K.L., Abbink, P., et al. (2011). International seroepidemiology of adenovirus serotypes 5, 26, 35, and 48 in pediatric and adult populations. Vaccine 29, 5203-5209.

Barr, P.J. (1991). Recombinant Pfs25 protein of Plasmodium falciparum elicits malaria transmission-blocking immunity in experimental animals. Journal of Experimental Medicine 174, 1203-1208.

Bingham, A., Gaspar, F., Lancaster, K., Conjera, J., Collymore, Y., and Ba-Nguz, A. (2012). Community perceptions of malaria and vaccines in two districts of Mozambique. Malaria Journal 11, 394.

Blackman, M.J., Heidrich, H.G., Donachie, S., McBride, J.S., and Holder, A.A. (1990). A single fragment of a malaria merozoite surface protein remains on the parasite during red cell invasion and is the target of invasion-inhibiting antibodies. J. Exp. Med. 172, 379382.

Bouharoun-Tayoun, H., Oeuvray, C., Lunel, F., and Druilhe, P. (1995). Mechanisms underlying the monocyte-mediated antibody-dependent killing of Plasmodium falciparum asexual blood stages. J. Exp. Med. 182, 409-418.

Bruder, J.T., Stefaniak, M.E., Patterson, N.B., Chen, P., Konovalova, S., Limbach, K., Campo, J.J., Ettyreddy, D., Li, S., Dubovsky, F., et al. (2010). Adenovectors induce functional antibodies capable of potent inhibition of blood stage malaria parasite growth. Vaccine 28, 3201-3210.

Bruna-Romero, O., Rocha, C.D., Tsuji, M., and Gazzinelli, R.T. (2004). Enhanced protective immunity against malaria by vaccination with a recombinant adenovirus encoding the circumsporozoite protein of Plasmodium lacking the GPI-anchoring motif. Vaccine 22, 3575-3584.

Bull, P.C., Lowe, B.S., Kortok, M., Molyneux, C.S., Newbold, C.I., and Marsh, K. (1998). Parasite antigens on the infected red cell surface are targets for naturally acquired immunity to malaria. Nature Medicine 4, 358-360.

Butler, N.S., Moebius, J., Pewe, L.L., Traore, B., Doumbo, O.K., Tygrett, L.T., Waldschmidt, T.J., Crompton, P.D., and Harty, J.T. (2012). Therapeutic blockade of PD-L1 and LAG-3 rapidly clears established blood-stage Plasmodium infection. Nat. Immunol. 13, 188-195. 
Casella, C.R., and Mitchell, T.C. (2008). Putting endotoxin to work for us: Monophosphoryl lipid A as a safe and effective vaccine adjuvant. Cellular and Molecular Life Sciences 65, $3231-3240$.

Cassidy, W.M., Watson, B., Ioli, V.A., Williams, K., Bird, S., and West, D.J. (2001). A randomized trial of alternative two- and three-dose hepatitis B vaccination regimens in adolescents: antibody responses, safety, and immunologic memory. Pediatrics 107, 626631.

Clyde, D.F., Most, H., McCarthy, V.C., and Vanderberg, J.P. (1973). Immunization of man against sporozite-induced falciparum malaria. Am. J. Med. Sci. 266, 169-177.

Cochrane, A., Nussenzweig, R., and Nardin, E. (1980). Malaria. 3: Immunology and immunization (New York: Academic Press).

Cohen, J.M., Smith, D.L., Cotter, C., Ward, A., Yamey, G., Sabot, O.J., and Moonen, B. (2012). Malaria resurgence: a systematic review and assessment of its causes. Malaria Journal 11, 122.

Collins, W.E., and Jeffery, G.M. (1999). A retrospective examination of secondary sporozoiteand trophozoite-induced infections with Plasmodium falciparum: development of parasitologic and clinical immunity following secondary infection. Am. J. Trop. Med. Hyg. 61, 20-35.

Courtin, D., Oesterholt, M., Huismans, H., Kusi, K., Milet, J., Badaut, C., Gaye, O., Roeffen, W., Remarque, E.J., Sauerwein, R., et al. (2009). The quantity and quality of African children's IgG responses to merozoite surface antigens reflect protection against Plasmodium falciparum malaria. PLoS ONE 4, e7590.

Das, D., Tripura, R., Phyo, A.P., Lwin, K.M., Tarning, J., Lee, S.J., Hanpithakpong, W., Stepniewska, K., Menard, D., Ringwald, P., et al. (2013). Effect of high-dose or splitdose artesunate on parasite clearance in artemisinin-resistant falciparum malaria. Clin. Infect. Dis. 56, e48-e58.

Daubenberger, C.A. (2012). First clinical trial of purified, irradiated malaria sporozoites in humans. Expert Rev Vaccines 11, 31-33.

Van Der Wielen, M., Van Damme, P., and Collard, F. (2000). A two dose schedule for combined hepatitis A and hepatitis B vaccination in children ages one to eleven years. Pediatr. Infect. Dis. J. 19, 848-853.

Didierlaurent, A.M., Morel, S., Lockman, L., Giannini, S.L., Bisteau, M., Carlsen, H., Kielland, A., Vosters, O., Vanderheyde, N., Schiavetti, F., et al. (2009). AS04, an Aluminum Saltand TLR4 Agonist-Based Adjuvant System, Induces a Transient Localized Innate Immune Response Leading to Enhanced Adaptive Immunity. The Journal of Immunology 183, 6186-6197. 
Dobson, M.J., Malowany, M., and Snow, R.W. (2000). Malaria control in East Africa: the Kampala Conference and the Pare-Taveta Scheme: a meeting of common and high ground. Parassitologia 42, 149-166.

Dupuis, M., Denis-Mize, K., LaBarbara, A., Peters, W., Charo, I.F., McDonald, D.M., and Ott, G. (10AD). Immunization with the adjuvant MF59 induces macrophage trafficking and apoptosis. European Journal of Immunology 31, 2910-2918.

Eisenbarth, S.C., Colegio, O.R., O’Connor, W., Sutterwala, F.S., and Flavell, R.A. (2008). Crucial role for the Nalp3 inflammasome in the immunostimulatory properties of aluminium adjuvants. Nature 453, 1122-1126.

Enayati, A., and Hemingway, J. (2010). Malaria management: past, present, and future. Annu. Rev. Entomol. 55, 569-591.

Epstein, J.E., Tewari, K., Lyke, K.E., Sim, B.K.L., Billingsley, P.F., Laurens, M.B., Gunasekera, A., Chakravarty, S., James, E.R., Sedegah, M., et al. (2011). Live attenuated malaria vaccine designed to protect through hepatic $\mathrm{CD}^{+} \mathrm{T}$ cell immunity. Science 334 , $475-480$.

Eziefula, A.C., Bousema, T., Yeung, S., Kamya, M., Owaraganise, A., Gabagaya, G., Bradley, J., Grignard, L., Lanke, K.H.W., Wanzira, H., et al. (2014). Single dose primaquine for clearance of Plasmodium falciparum gametocytes in children with uncomplicated malaria in Uganda: a randomised, controlled, double-blind, dose-ranging trial. The Lancet Infectious Diseases 14, 130-139.

Farrance, C.E., Chichester, J.A., Musiychuk, K., Shamloul, M., Rhee, A., Manceva, S.D., Jones, R.M., Mamedov, T., Sharma, S., Mett, V., et al. (2011). Antibodies to plantproduced Plasmodium falciparum sexual stage protein Pfs 25 exhibit transmission blocking activity. Human Vaccines 7, 191-198.

Fidock, D.A. (2013). Eliminating Malaria. Science 340, 1531-1533.

Flach, T.L., Ng, G., Hari, A., Desrosiers, M.D., Zhang, P., Ward, S.M., Seamone, M.E., Vilaysane, A., Mucsi, A.D., Fong, Y., et al. (2011). Alum interaction with dendritic cell membrane lipids is essential for its adjuvanticity. Nature Medicine 17, 479-487.

Flehmig, B., Staedele, H., Xueref, C., Vidor, E., Zuckerman, J., and Zuckerman, A. (1997). Early appearance of neutralizing antibodies after vaccination with an inactivated hepatitis A vaccine. Journal of Infection 35, 37-40.

Fowkes, F.J.I., Richards, J.S., Simpson, J.A., and Beeson, J.G. (2010). The relationship between anti-merozoite antibodies and incidence of Plasmodium falciparum malaria: A systematic review and meta-analysis. PLoS Med. 7, e1000218. 
Freund, J., Casals, J., and Hosmer, E.P. (1937). Sensitization and Antibody Formation after Injection of Tubercle Bacilli and Paraffin Oil. Experimental Biology and Medicine 37, 509-513.

Gabitzsch, E.S., Xu, Y., Yoshida, L.H., Balint, J., Amalfitano, A., and Jones, F.R. (2009). Novel Adenovirus type 5 vaccine platform induces cellular immunity against HIV-1 Gag, Pol, Nef despite the presence of Ad5 immunity. Vaccine 27, 6394-6398.

Garçon, N., Vaughn, D.W., and Didierlaurent, A.M. (2012). Development and evaluation of AS03, an Adjuvant System containing $\alpha$-tocopherol and squalene in an oil-in-water emulsion. Expert Review of Vaccines 11, 349-366.

Gavin, A.L., Hoebe, K., Duong, B., Ota, T., Martin, C., Beutler, B., and Nemazee, D. (2006). Adjuvant-Enhanced Antibody Responses in the Absence of Toll-Like Receptor Signaling. Science 314, 1936-1938.

Girard, A., Saron, W., Bergeron-Sandoval, L.-P., Sarhan, F., and Archambault, D. (2011). Flagellin produced in plants is a potent adjuvant for oral immunization. Vaccine 29, 6695-6703.

Glenny, A.T., Pope, C.G., Waddington, H., and Wallace, U. (1926). Immunological notes. XVII-XXIV. The Journal of Pathology and Bacteriology 29, 31-40.

Goodman, A.L., Blagborough, A.M., Biswas, S., Wu, Y., Hill, A.V., Sinden, R.E., and Draper, S.J. (2011). A viral vectored prime-boost immunization regime targeting the malaria Pfs25 antigen induces transmission-blocking activity. PLoS ONE 6, e29428.

Gregory, J.A., Li, F., Tomosada, L.M., Cox, C.J., Topol, A.B., Vinetz, J.M., and Mayfield, S. (2012). Algae-Produced Pfs25 Elicits Antibodies That Inhibit Malaria Transmission. PLoS ONE 7, e37179.

Griffin, J.T., Hollingsworth, T.D., Okell, L.C., Churcher, T.S., White, M., Hinsley, W., Bousema, T., Drakeley, C.J., Ferguson, N.M., Basáñez, M.-G., et al. (2010). Reducing Plasmodium falciparum Malaria Transmission in Africa: A Model-Based Evaluation of Intervention Strategies. PLoS Medicine 7, e1000324.

Gupta, S., Snow, R.W., Donnelly, C.A., Marsh, K., and Newbold, C. (1999). Immunity to noncerebral severe malaria is acquired after one or two infections. Nat. Med. 5, 340-343.

Hartman, Z.C., Appledorn, D.M., and Amalfitano, A. (2008). Adenovirus vector induced innate immune responses: impact upon efficacy and toxicity in gene therapy and vaccine applications. Virus Res. 132, 1-14.

He, T.C., Zhou, S., da Costa, L.T., Yu, J., Kinzler, K.W., and Vogelstein, B. (1998). A simplified system for generating recombinant adenoviruses. Proc. Natl. Acad. Sci. U.S.A. 95, 2509-2514. 
Hem, S.L., and White, J.L. (1995). Structure and Properties of Aluminum-Containing Adjuvants. In Vaccine Design, M.F. Powell, and M.J. Newman, eds. (Boston, MA: Springer US), pp. 249-276.

Holder, A.A. (2009). The carboxy-terminus of merozoite surface protein 1: structure, specific antibodies and immunity to malaria. Parasitology 136, 1445-1456.

Hviid, L. (2007). Development of vaccines against Plasmodium falciparum malaria: taking lessons from naturally acquired protective immunity. Microbes Infect. 9, 772-776.

Jasani, B., Navabi, H., and Adams, M. (2009). Ampligen: A potential toll-like 3 receptor adjuvant for immunotherapy of cancer. Vaccine 27, 3401-3404.

Kaslow, D.C., and Shiloach, J. (1994). Production, Purification and Immunogenicity of a Malaria Transmission-Blocking Vaccine Candidate: TBV25H Expressed in Yeast and Purified Using Nickel-NTA Agarose. Bio/Technology 12, 494-499.

Kaslow, D.C., Quakyi, I.A., Syin, C., Raum, M.G., Keister, D.B., Coligan, J.E., McCutchan, T.F., and Miller, L.H. (1988). A vaccine candidate from the sexual stage of human malaria that contains EGF-like domains. Nature 333, 74-76.

Kaslow, D.C., Bathurst, I.C., Isaacs, S.N., Keister, D.B., Moss, B., and Barr, P.J. (1992). Induction of Plasmodium falciparum transmission-blocking antibodies by recombinant Pfs25. Mem. Inst. Oswaldo Cruz 87 Suppl 3, 175-177.

Kaslow, D.C., Bathurst, I.C., Lensen, T., Ponnudurai, T., Barr, P.J., and Keister, D.B. (1994). Saccharomyces cerevisiae recombinant Pfs 25 adsorbed to alum elicits antibodies that block transmission of Plasmodium falciparum. Infect. Immun. 62, 5576-5580.

Kinyanjui, S.M., Bejon, P., Osier, F.H., Bull, P.C., and Marsh, K. (2009). What you see is not what you get: implications of the brevity of antibody responses to malaria antigens and transmission heterogeneity in longitudinal studies of malaria immunity. Malar. J. 8, 242.

Kool, M., Soullie, T., van Nimwegen, M., Willart, M.A.M., Muskens, F., Jung, S., Hoogsteden, H.C., Hammad, H., and Lambrecht, B.N. (2008a). Alum adjuvant boosts adaptive immunity by inducing uric acid and activating inflammatory dendritic cells. Journal of Experimental Medicine 205, 869-882.

Kool, M., Pétrilli, V., De Smedt, T., Rolaz, A., Hammad, H., van Nimwegen, M., Bergen, I.M., Castillo, R., Lambrecht, B.N., and Tschopp, J. (2008b). Cutting edge: alum adjuvant stimulates inflammatory dendritic cells through activation of the NALP3 inflammasome. J. Immunol. 181, 3755-3759.

Kubler-Kielb, J., Majadly, F., Wu, Y., Narum, D.L., Guo, C., Miller, L.H., Shiloach, J., Robbins, J.B., and Schneerson, R. (2007). Long-lasting and transmission-blocking 
activity of antibodies to Plasmodium falciparum elicited in mice by protein conjugates of Pfs25. Proceedings of the National Academy of Sciences 104, 293-298.

Ter Kuile, F., White, N.J., Holloway, P., Pasvol, G., and Krishna, S. (1993). Plasmodium falciparum: in vitro studies of the pharmacodynamic properties of drugs used for the treatment of severe malaria. Exp. Parasitol. 76, 85-95.

Kumar, R., Angov, E., and Kumar, N. (2014). Potent Malaria Transmission-Blocking Antibody Responses Elicited by Plasmodium falciparum Pfs25 Expressed in Escherichia coli after Successful Protein Refolding. Infection and Immunity 82, 1453-1459.

Langhorne, J., Ndungu, F.M., Sponaas, A.-M., and Marsh, K. (2008). Immunity to malaria: more questions than answers. Nature Immunology 9, 725-732.

Limbach, K.J., and Richie, T.L. (2009). Viral vectors in malaria vaccine development. Parasite Immunol. 31, 501-519.

malERA Consultative Group on Vector Control (2011). A research agenda for malaria eradication: vector control. PLoS Med. 8, e1000401.

Marichal, T., Ohata, K., Bedoret, D., Mesnil, C., Sabatel, C., Kobiyama, K., Lekeux, P., Coban, C., Akira, S., Ishii, K.J., et al. (2011). DNA released from dying host cells mediates aluminum adjuvant activity. Nature Medicine 17, 996-1002.

McCoy, K., Tatsis, N., Korioth-Schmitz, B., Lasaro, M.O., Hensley, S.E., Lin, S.-W., Li, Y., Giles-Davis, W., Cun, A., Zhou, D., et al. (2007). Effect of preexisting immunity to adenovirus human serotype 5 antigens on the immune responses of nonhuman primates to vaccine regimens based on human- or chimpanzee-derived adenovirus vectors. J. Virol. 81, 6594-6604.

McDevitt, M.A., Xie, J., Gordeuk, V., and Bucala, R. (2004). The anemia of malaria infection: role of inflammatory cytokines. Curr. Hematol. Rep. 3, 97-106.

McHeyzer-Williams, L.J., and McHeyzer-Williams, M.G. (2005). Antigen-specific memory B cell development. Annu. Rev. Immunol. 23, 487-513.

McKee, A.S., Burchill, M.A., Munks, M.W., Jin, L., Kappler, J.W., Friedman, R.S., Jacobelli, J., and Marrack, P. (2013). Host DNA released in response to aluminum adjuvant enhances MHC class II-mediated antigen presentation and prolongs CD4 T-cell interactions with dendritic cells. Proceedings of the National Academy of Sciences 110, E1122-E1131.

Miura, K., Takashima, E., Deng, B., Tullo, G., Diouf, A., Moretz, S.E., Nikolaeva, D., Diakite, M., Fairhurst, R.M., Fay, M.P., et al. (2013). Functional Comparison of Plasmodium falciparum Transmission-Blocking Vaccine Candidates by the Standard MembraneFeeding Assay. Infection and Immunity 81, 4377-4382. 
Moorthy, V.S., and Kieny, M.P. (2010). Reducing empiricism in malaria vaccine design. Lancet Infect Dis 10, 204-211.

Näslund, T.I., Uyttenhove, C., Nordström, E.K.L., Colau, D., Warnier, G., Jondal, M., Van den Eynde, B.J., and Liljeström, P. (2007). Comparative prime-boost vaccinations using Semliki Forest virus, adenovirus, and ALVAC vectors demonstrate differences in the generation of a protective central memory CTL response against the P815 tumor. J. Immunol. 178, 6761-6769.

Nebie, I., Diarra, A., Ouedraogo, A., Tiono, A.B., Konate, A.T., Gansane, A., Soulama, I., Cousens, S., Leroy, O., and Sirima, S.B. (2009). Humoral and cell-mediated immunity to MSP3 peptides in adults immunized with MSP3 in malaria endemic area, Burkina Faso. Parasite Immunol. 31, 474-480.

Newport, M.J., Goetghebuer, T., Weiss, H.A., Whittle, H., Siegrist, C.-A., Marchant, A., and MRC Gambia Twin Study Group (2004). Genetic regulation of immune responses to vaccines in early life. Genes Immun. 5, 122-129.

Noor, A.M., Kinyoki, D.K., Mundia, C.W., Kabaria, C.W., Mutua, J.W., Alegana, V.A., Fall, I.S., and Snow, R.W. (2014). The changing risk of Plasmodium falciparum malaria infection in Africa: 2000-10: a spatial and temporal analysis of transmission intensity. The Lancet $383,1739-1747$.

Nunes, J.K., Woods, C., Carter, T., Raphael, T., Morin, M.J., Diallo, D., Leboulleux, D., Jain, S., Loucq, C., Kaslow, D.C., et al. (2014). Development of a transmission-blocking malaria vaccine: Progress, challenges, and the path forward. Vaccine 32, 5531-5539.

Ochiel, D.O., Awandare, G.A., Keller, C.C., Hittner, J.B., Kremsner, P.G., Weinberg, J.B., and Perkins, D.J. (2005). Differential regulation of beta-chemokines in children with Plasmodium falciparum malaria. Infect. Immun. 73, 4190-4197.

Ogutu, B.R., Apollo, O.J., McKinney, D., Okoth, W., Siangla, J., Dubovsky, F., Tucker, K., Waitumbi, J.N., Diggs, C., Wittes, J., et al. (2009). Blood stage malaria vaccine eliciting high antigen-specific antibody concentrations confers no protection to young children in Western Kenya. PLoS ONE 4, e4708.

Ojakaa, D., Yamo, E., Collymore, Y., Ba-Nguz, A., and Bingham, A. (2011). Perceptions of malaria and vaccines in Kenya. Human Vaccines 7, 1096-1099.

Ouédraogo, A.L., Bousema, T., de Vlas, S.J., Cuzin-Ouattara, N., Verhave, J.-P., Drakeley, C., Luty, A.J.F., and Sauerwein, R. (2010). The plasticity of Plasmodium falciparum gametocytaemia in relation to age in Burkina Faso. Malar. J. 9, 281.

Palmer, I., and Wingfield, P.T. (2004). Preparation and Extraction of Insoluble (InclusionBody) Proteins from Escherichia coli. In Current Protocols in Protein Science, J.E. 
Coligan, B.M. Dunn, D.W. Speicher, and P.T. Wingfield, eds. (Hoboken, NJ, USA: John Wiley \& Sons, Inc.),

Pashine, A., Valiante, N.M., and Ulmer, J.B. (2005). Targeting the innate immune response with improved vaccine adjuvants. Nature Medicine 11, S63-S68.

Petrovsky, N., and Aguilar, J.C. (2004). Vaccine adjuvants: Current state and future trends. Immunology and Cell Biology 82, 488-496.

Qian, F., Wu, Y., Muratova, O., Zhou, H., Dobrescu, G., Duggan, P., Lynn, L., Song, G., Zhang, Y., Reiter, K., et al. (2007). Conjugating recombinant proteins to Pseudomonas aeruginosa ExoProtein A: a strategy for enhancing immunogenicity of malaria vaccine candidates. Vaccine 25, 3923-3933.

Qian, F., Rausch, K.M., Muratova, O., Zhou, H., Song, G., Diouf, A., Lambert, L., Narum, D.L., Wu, Y., Saul, A., et al. (2008). Addition of CpG ODN to recombinant Pseudomonas aeruginosa ExoProtein A conjugates of AMA1 and Pfs 25 greatly increases the number of responders. Vaccine 26, 2521-2527.

Ranson, H., Abdallah, H., Badolo, A., Guelbeogo, W.M., Kerah-Hinzoumbé, C., YangalbéKalnoné, E., Sagnon, N., Simard, F., and Coetzee, M. (2009). Insecticide resistance in Anopheles gambiae: data from the first year of a multi-country study highlight the extent of the problem. Malar. J. 8, 299.

Reyes-Sandoval, A., Sridhar, S., Berthoud, T., Moore, A.C., Harty, J.T., Gilbert, S.C., Gao, G., Ertl, H.C.J., Wilson, J.C., and Hill, A.V.S. (2008). Single-dose immunogenicity and protective efficacy of simian adenoviral vectors against Plasmodium berghei. Eur. J. Immunol. 38, 732-741.

Rodrigues, E.G., Zavala, F., Eichinger, D., Wilson, J.M., and Tsuji, M. (1997). Single immunizing dose of recombinant adenovirus efficiently induces CD8+ T cell-mediated protective immunity against malaria. J. Immunol. 158, 1268-1274.

Rodrigues, E.G., Zavala, F., Nussenzweig, R.S., Wilson, J.M., and Tsuji, M. (1998). Efficient induction of protective anti-malaria immunity by recombinant adenovirus. Vaccine 16 , $1812-1817$.

Roestenberg, M., Teirlinck, A.C., McCall, M.B.B., Teelen, K., Makamdop, K.N., Wiersma, J., Arens, T., Beckers, P., van Gemert, G., van de Vegte-Bolmer, M., et al. (2011). Longterm protection against malaria after experimental sporozoite inoculation: an open-label follow-up study. Lancet 377, 1770-1776.

Saxena, A.K., Singh, K., Su, H.-P., Klein, M.M., Stowers, A.W., Saul, A.J., Long, C.A., and Garboczi, D.N. (2006). The essential mosquito-stage P25 and P28 proteins from Plasmodium form tile-like triangular prisms. Nature Structural \&\#38; Molecular Biology 13, 90-91. 
Schwartz, E., Parise, M., Kozarsky, P., and Cetron, M. (2003). Delayed onset of malaria-implications for chemoprophylaxis in travelers. N. Engl. J. Med. 349, 1510-1516.

Schwartz, L., Brown, G.V., Genton, B., and Moorthy, V.S. (2012). A review of malaria vaccine clinical projects based on the WHO rainbow table. Malaria Journal 11, 11.

Sedegah, M., Tamminga, C., McGrath, S., House, B., Ganeshan, H., Lejano, J., Abot, E., Banania, G.J., Sayo, R., Farooq, F., et al. (2011). Adenovirus 5-vectored P. falciparum vaccine expressing CSP and AMA1. Part A: safety and immunogenicity in seronegative adults. PLoS ONE 6, e24586.

Seubert, A., Monaci, E., Pizza, M., O’Hagan, D.T., and Wack, A. (2008). The adjuvants aluminum hydroxide and MF59 induce monocyte and granulocyte chemoattractants and enhance monocyte differentiation toward dendritic cells. J. Immunol. 180, 5402-5412.

Seubert, A., Calabro, S., Santini, L., Galli, B., Genovese, A., Valentini, S., Aprea, S., Colaprico, A., D’Oro, U., Giuliani, M.M., et al. (2011). Adjuvanticity of the oil-in-water emulsion MF59 is independent of Nlrp3 inflammasome but requires the adaptor protein MyD88. Proceedings of the National Academy of Sciences 108, 11169-11174.

Shott, J.P., McGrath, S.M., Pau, M.G., Custers, J.H.V., Ophorst, O., Demoitié, M.-A., Dubois, M.-C., Komisar, J., Cobb, M., Kester, K.E., et al. (2008). Adenovirus 5 and 35 vectors expressing Plasmodium falciparum circumsporozoite surface protein elicit potent antigen-specific cellular IFN- $\gamma$ and antibody responses in mice. Vaccine 26, 2818-2823.

Sinden, R.E., Carter, R., Drakeley, C., and Leroy, D. (2012). The biology of sexual development of Plasmodium: the design and implementation of transmission-blocking strategies. Malaria Journal 11, 70 .

Sinkins, S.P., and Gould, F. (2006). Gene drive systems for insect disease vectors. Nat. Rev. Genet. 7, 427-435.

Sirima, S.B., Nébié, I., Ouédraogo, A., Tiono, A.B., Konaté, A.T., Gansané, A., Dermé, A.I., Diarra, A., Ouédraogo, A., Soulama, I., et al. (2007). Safety and immunogenicity of the Plasmodium falciparum merozoite surface protein-3 long synthetic peptide (MSP3-LSP) malaria vaccine in healthy, semi-immune adult males in Burkina Faso, West Africa. Vaccine 25, 2723-2732.

Sixt, M., Kanazawa, N., Selg, M., Samson, T., Roos, G., Reinhardt, D.P., Pabst, R., Lutz, M.B., and Sorokin, L. (2005). The Conduit System Transports Soluble Antigens from the Afferent Lymph to Resident Dendritic Cells in the T Cell Area of the Lymph Node. Immunity 22, 19-29.

Smith, D.L., Hay, S.I., Noor, A.M., and Snow, R.W. (2009). Predicting changing malaria risk after expanded insecticide-treated net coverage in Africa. Trends in Parasitology 25, 511516. 
Snow, R.W., Amratia, P., Kabaria, C.W., Noor, A.M., and Marsh, K. (2012). The Changing Limits and Incidence of Malaria in Africa. In Advances in Parasitology, (Elsevier), pp. 169-262.

Sokolovska, A., Hem, S., and Hogenesch, H. (2007). Activation of dendritic cells and induction of CD4+ T cell differentiation by aluminum-containing adjuvants. Vaccine 25, 45754585 .

Sørensen, H.P., and Mortensen, K.K. (2005). Advanced genetic strategies for recombinant protein expression in Escherichia coli. Journal of Biotechnology 115, 113-128.

Stowers, A.W., Keister, D.B., Muratova, O., and Kaslow, D.C. (2000). A region of Plasmodium falciparum antigen Pfs 25 that is the target of highly potent transmissionblocking antibodies. Infect. Immun. 68, 5530-5538.

$\mathrm{Su}, \mathrm{X}$., Hayton, K., and Wellems, T.E. (2007). Genetic linkage and association analyses for trait mapping in Plasmodium falciparum. Nat. Rev. Genet. 8, 497-506.

Takala, S.L., and Plowe, C.V. (2009). Genetic diversity and malaria vaccine design, testing and efficacy: preventing and overcoming "vaccine resistant malaria." Parasite Immunol. 31, $560-573$.

Tamminga, C., Sedegah, M., Regis, D., Chuang, I., Epstein, J.E., Spring, M., MendozaSilveiras, J., McGrath, S., Maiolatesi, S., Reyes, S., et al. (2011). Adenovirus-5-vectored P. falciparum vaccine expressing CSP and AMA1. Part B: safety, immunogenicity and protective efficacy of the CSP component. PLoS ONE 6, e25868.

Tanaka, T.Q., Dehdashti, S.J., Nguyen, D.-T., McKew, J.C., Zheng, W., and Williamson, K.C. (2013). A quantitative high throughput assay for identifying gametocytocidal compounds. Molecular and Biochemical Parasitology 188, 20-25.

Taverne, J., Tavernier, J., Fiers, W., and Playfair, J.H. (1987). Recombinant tumour necrosis factor inhibits malaria parasites in vivo but not in vitro. Clin. Exp. Immunol. 67, 1-4.

Taylor, W.R.J., and White, N.J. (2004). Antimalarial drug toxicity: a review. Drug Saf 27, 2561.

Taylor, D.N., Treanor, J.J., Strout, C., Johnson, C., Fitzgerald, T., Kavita, U., Ozer, K., Tussey, L., and Shaw, A. (2011). Induction of a potent immune response in the elderly using the TLR-5 agonist, flagellin, with a recombinant hemagglutinin influenza-flagellin fusion vaccine (VAX125, STF2.HA1 SI). Vaccine 29, 4897-4902.

Terenius, O., Marinotti, O., Sieglaff, D., and James, A.A. (2008). Molecular genetic manipulation of vector mosquitoes. Cell Host Microbe 4, 417-423.

Tsai, C.W., Duggan, P.F., Shimp, R.L., Miller, L.H., and Narum, D.L. (2006). Overproduction of Pichia pastoris or Plasmodium falciparum protein disulfide isomerase affects 
expression, folding and O-linked glycosylation of a malaria vaccine candidate expressed in P. pastoris. Journal of Biotechnology 121, 458-470.

Tsuboi, T., Takeo, S., Iriko, H., Jin, L., Tsuchimochi, M., Matsuda, S., Han, E.-T., Otsuki, H., Kaneko, O., Sattabongkot, J., et al. (2008). Wheat Germ Cell-Free System-Based Production of Malaria Proteins for Discovery of Novel Vaccine Candidates. Infection and Immunity 76, 1702-1708.

Udhayakumar, V., Kariuki, S., Kolczack, M., Girma, M., Roberts, J.M., Oloo, A.J., Nahlen, B.L., and Lal, A.A. (2001). Longitudinal study of natural immune responses to the Plasmodium falciparum apical membrane antigen (AMA-1) in a holoendemic region of malaria in western Kenya: Asembo Bay Cohort Project VIII. Am. J. Trop. Med. Hyg. 65, $100-107$.

Vollmer, J., Weeratna, R., Payette, P., Jurk, M., Schetter, C., Laucht, M., Wader, T., Tluk, S., Liu, M., Davis, H.L., et al. (2004). Characterization of three $\mathrm{CpG}$ oligodeoxynucleotide classes with distinct immunostimulatory activities. European Journal of Immunology 34, 251-262.

Vuola, J.M., Keating, S., Webster, D.P., Berthoud, T., Dunachie, S., Gilbert, S.C., and Hill, A.V.S. (2005). Differential immunogenicity of various heterologous prime-boost vaccine regimens using DNA and viral vectors in healthy volunteers. J. Immunol. 174, 449-455.

White, N.J. (1996). The treatment of malaria. N. Engl. J. Med. 335, 800-806.

White, N.J., Qiao, L., Qi, G., and Luzzatto, L. (2012). Rationale for recommending a lower dose of primaquine as a Plasmodium falciparum gametocytocide in populations where G6PD deficiency is common. Malaria Journal 11, 418 .

Wu, Y., Przysiecki, C., Flanagan, E., Bello-Irizarry, S.N., Ionescu, R., Muratova, O., Dobrescu, G., Lambert, L., Keister, D., Rippeon, Y., et al. (2006). Sustained high-titer antibody responses induced by conjugating a malarial vaccine candidate to outer-membrane protein complex. Proceedings of the National Academy of Sciences 103, 18243-18248.

Wu, Y., Ellis, R.D., Shaffer, D., Fontes, E., Malkin, E.M., Mahanty, S., Fay, M.P., Narum, D., Rausch, K., Miles, A.P., et al. (2008). Phase 1 trial of malaria transmission blocking vaccine candidates Pfs 25 and Pvs25 formulated with montanide ISA 51. PLoS ONE 3, e2636.

Xiang, Z.Q., Yang, Y., Wilson, J.M., and Ertl, H.C. (1996). A replication-defective human adenovirus recombinant serves as a highly efficacious vaccine carrier. Virology 219, 220-227.

(2014a). Severe malaria. Trop. Med. Int. Health 19 Suppl 1, 7-131.

(2014b). World Malaria Report (Geneva, Switzerland: World Health Organization). 
VITA

Lukasz Sewera was born in Gliwice, Poland in 1988 and grew up in Chicago after moving there in 1992. After graduating high school in 2007, he went to Illinois Wesleyan to earn a Bachelor of Science degree magna cum laude in biology, minoring in biochemistry. While there he was involved in research in the fields of zoology and pathology. In 2011 he started medical school at Loyola University Chicago Stritch School of Medicine. In 2013 he joined the master's program in Microbiology and Immunology. After completing the master's degree, he will return to medical school to complete the final two years. 
